University of Nebraska - Lincoln

DigitalCommons@University of Nebraska - Lincoln

Management Department Faculty Publications

Management Department

6-2009

Complexity Leadership in Bureaucratic Forms of Organizing: A

Meso Model

Mary Uhl-Bien

University of Nebraska-Lincoln, mbien2@unl.edu

Russ Marion

College of Education, Clemson University, Clemson, SC, marion2@clemson.edu

Follow this and additional works at: https://digitalcommons.unl.edu/managementfacpub

Part of the Management Sciences and Quantitative Methods Commons

Uhl-Bien, Mary and Marion, Russ, "Complexity Leadership in Bureaucratic Forms of Organizing: A Meso Model" (2009). Management Department Faculty Publications. 38.

https://digitalcommons.unl.edu/managementfacpub/38

This Article is brought to you for free and open access by the Management Department at DigitalCommons@University of Nebraska - Lincoln. It has been accepted for inclusion in Management Department Faculty Publications by an authorized administrator of DigitalCommons@University of Nebraska - Lincoln. 
Published in The Leadership Quarterly 20:4 (August 2009), pp. 631-650; special issue on “Meso-Modeling of Leadership: Integrating Micro- and Macro-Perspectives of Leadership"; doi: 10.1016/j.leaqua.2009.04.007 Copyright @ 2009 Elsevier Inc. Used by permission. http://www.elsevier.com/locate/leaqua

Published online June 16, 2009.

\title{
Complexity Leadership in Bureaucratic Forms of Organizing: A Meso Model
}

\author{
Mary Uhl-Bien Department of Management, University of Nebraska-Lincoln, P.O. Box 880491, Lincoln, NE \\ 68588-0491, USA; tel 402 472-2314, email mbien2@unl.edu (Corresponding author)
}

\author{
Russ Marion Educational Leadership, School of Education, Clemson University, Clemson, SC 29631-0710, USA; \\ tel 864 656-5105, email Marion2@clemson.edu
}

\begin{abstract}
We consider Complexity Leadership Theory in contexts of bureaucratic forms of organizing to describe how adaptive dynamics can work in combination with administrative functions to generate emergence and change in organizations. Complexity leadership approaches are consistent with the central assertion of the meso argument that leadership is multi-level, processual, contextual, and interactive. In this paper we focus on the adaptive function, an interactive process between adaptive leadership (an agentic behavior) and complexity dynamics (non-agentic social dynamics) that generates emergent outcomes (e.g., innovation, learning, adaptability) for the firm. Propositions regarding the actions of complexity leadership in bureaucratic forms of organizing are offered.
\end{abstract}

Keywords complexity leadership theory, adaptive leadership, complex adaptive systems (CAS), bureaucracy, emergence, innovation, adaptability

In recent years, scholars have begun to develop new approaches to leadership grounded in complexity theory (Boal and Schlultz, 2007; Hazy, 2007; Lichtenstein et al., 2006; Lord, 2008; Marion and Uhl-Bien, 2001; McKelvey, 2003a; Osborn and Hunt, 2007; Plowman et al., 2007; Schreiber and Carley, 2008; Schneider, 2002; Schneider and Somers, 2006; Surie and Hazy, 2006; Uhl-Bien et al., 2007). These approaches are motivated by the desire to develop leadership models that more accurately reflect the complex nature of leadership as it occurs in practice (cf. Snowden \& Boone, 2007). They represent a growing sentiment that traditional models of leadership are insufficient for understanding the dynamic, distributed, and contextual nature of leadership in organizations (Gronn, 2002; Hunt and Dodge, 2000; Johannessen and Stacey, 2005; Marion and Uhl-Bien, 2001; McKelvey, 2008; Osborn et al., 2002; Rost, 1991; Stacey, 1993; Stacey, 2003).

At its most basic level, Complexity Leadership Theory (CLT) is about leadership in and of complex adaptive systems, or CAS. CAS are neural-like networks of interacting, interdependent agents who are bonded in a collective dynamic by common need (Cilliers, 1998; Holland, 1995; Langston, 1986; Marion, 1999). They are capable of solving problems creatively and are able to learn and adapt quickly (Carley and Hill, 2001; Carley and Lee, 1998; Goodwin, 1994; Levy, 1992). As described by Levy (1992, cited in Boal \& Schlultz, 2007, p. 413):

A complex system is one whose component parts interact with sufficient intricacy that they cannot be predicted by standard linear equations; so many variables are at work in the system that its over-all behavior can only be understood as an emergent consequence of the holistic sum of the myriad behaviors embedded within. Reductionism does not work with complex systems, and it is now clear that a purely reductionist approach cannot be applied; ...in living systems the whole is more than the sum of its parts. This is the result of....complexity which allows certain behaviors and characteristics to emerge unbidden. (pp. 7-8).

The value of adding a CAS perspective to leadership is that it offers a paradigm for thinking about leadership from which we can more easily explore issues that confound us from a traditional view - issues of shared, distributed, collective, relational, dynamic, emergent and adaptive leadership processes (Drath et al., in press; Gronn, 2002; Brown and 
Gioia, 2002; Pearce and Conger, 2003). Complexity theory allows us to explore these issues by focusing on agent interaction through CAS dynamics - the emergent properties through which CAS form and operate.

In the present paper we develop a meso model of Complexity Leadership Theory (CLT) for bureaucratic forms of organizing. CLT is a change model of leadership that helps administrative leaders understand how to design robust, dynamically adapting organizations and how to utilize an often untapped resource: the informal dynamics within an organization. We ground our model in classic work on informal behaviors in organizations (Barnard, 1938; Homans, 1950; Selznick, 1949), but we extend beyond these views to explore the interactive, emergent and dynamic nature-the CAS dynamics-of this informal organization.

An important point to note about our framework is that the term "complexity" is not intended to mean "complicated," as was suggested by systems and contingency theorists in the mid-twentieth century (Buckley, 1967; Perrow, 1972). Rather, complexity is a specific term drawn from complexity science (cf. Snowden \& Boone, 2007) that refers to the "complex" (CAS) dynamics that result from a rich, evolving interaction of simple elements responding to the limited information with which each of them is presented (Cilliers, 1998). CAS dynamics represent the self-organizing mechanisms through which complex systems develop and change their internal structure spontaneously and adaptively to cope with (or manipulate) their environment (Cilliers, 1998). Complexity leadership, then, is about leadership in and of complex (CAS) dynamics. We turn to this important point next.

\section{Complexity Leadership Theory}

Complexity Leadership Theory (CLT) is the study of the interactive dynamics of complex systems (CAS) embedded within contexts of larger organizing systems. The significance of CAS dynamics for the study of leadership can only be understood by recognizing the meaning of the term complexity (see Cilliers, 1998, Ch. 1 for a good overview of complexity and CAS; see also Snowden \& Boone, 2007).

In complexity science, complexity does not mean a lot of pieces or parts, or being intricate (i.e., "complicated"), as in traditional usage. If one interprets complex or complexity to mean complicated they are missing the point (and missing the paradigm shift that complexity offers, see Plowman \& Duchon, 2008). Instead, its usage conveys a sense of rich interconnectedness and dynamic interaction that is generative of emergence in and among CAS. As described by Cilliers (1998, see p. viii), if a system can be given a complete description in terms of its individual constituents (despite a huge number of components), it is merely complicated-e.g., jumbo jets or computers are complicated. If relationships in a system cannot be fully explained by analyzing its individual components because they are not fixed but shifting and changing, it is complex (e.g., the brain is complex). This complexity results in novel features (e.g., self-organization) usually referred to as emergent properties. For example, natural language, the Brazilian rainforest and social systems are complex because they are richly interactive, emergent, nonlinearly dynamic, and unpredictable (Cilliers, 1998; Snowden and Boone, 2007, November).

In Complexity Leadership Theory such complexity (CAS) can be seen as occurring in a variety of organizing systems, including bureaucracy (the focus of this paper), network structures (e.g., terrorist networks, see Marion \& Uhl-Bien, 2003), open source systems (e.g., Linux, cf. O'Mahony \& Ferraro, 2007), markets (e.g., one may view an entire organization as a CAS operating in a market system), heterarchy (Fairtlough, 2005), "starfish" organizations (Brafman \& Beckstrom, 2006), etc.* Alternatively, the organizing system of interest in the study of complexity leadership may be the CAS itself. The type of organizing system in which CAS are embedded will necessarily change the issue of primary importance in the study of complexity leadership. For example, in bureaucratic organizations that are organized around administrative functions, the primary focus of CLT will be on entanglement between adaptive dynamics (CAS) and administrative structures (bureaucracy). In network organizations absent of clearly identified formal administrative functions, the focus will be more on network and self-organizing dynamics (see Marion \& Uhl-Bien (2003) analysis of al Qaeda). In markets the focus will be on CAS within the context of market forces.

Hence, CLT is a contextual theory of leadership - it describes leadership as necessarily embedded in context and "socially constructed in and from a context" (Osborn et al., 2002, p. 798). To study it requires consideration and examination of context in both theorizing and operationalization. In the present paper, since the focus of this special issue is on meso modeling-a concept appropriate to bureaucratic structures and systems-we will focus on complexity leadership in the context of bureaucratic forms of organizing. We will show how CLT can be used to develop a meso model of leadership in bureaucratic organizational systems.

Since complexity leadership is a "change model" of leadership, we will present a complexity framework for change leadership that focuses on enabling the learning, innovative, and adaptive capacity of complex adaptive systems (CAS) within larger bureaucratic structures. In this model, we will recognize both the formal, administrative (bureaucratic) and the informal, complexly dynamic (emergent) nature of change in organizational bureaucracies.

\subsection{Complexity leadership in bureaucratic organizational forms}

As defined by Weber (1947), bureaucratic structures are hierarchical, coordinated by rules, functionally departmentalized, and impersonal. According to Thompson (1967), Jaques (1989), and others, bureaucracy is structurally organized into production functions (e.g., line work), organizational functions (e.g., middle management), and executive functions (e.g., top management, strategic). In today's environment, the vast majority of formal organizations are organized around bureaucratic principles, and bureaucracy provides the context for the bulk of leadership theorizing in organizational studies.

* We thank Miguel Cunha, Universidad Nova de Lisboa, for pointing out the importance of CAS in these conditions. 
We propose, however, that the artificial barriers created by functionally departmentalized structures (clearly defined responsibilities that are only interdependent with other responsibilities in a linear or sequential fashion) is both descriptively unrealistic (akin to drawing a tree as a perfect circle) and, to the extent it is implemented, counterproductive. Real organizations have fuzzy boundaries between functions, and creative, adaptive organizations in particular-the focus of this paper-operate in a more informal and nonlinear fashion. Creative, adaptive organizations generate functions that work across boundaries and exhibit meso interactive dynamics - they are a blend of structured and dynamic behaviors. As such, bureaucratic organizations have both formal and informal systems (Crozier, 1964; Roethlisberger and Dickson, 1939; Trist and Bamforth, 1951), and our meso model is organized around the interplay between administrative (formal) and adaptive (informal; cf. Barnard, 1938; Selznick, 1949) functions. The formal (bureaucratic) function represents stated, sought-after goals of administrative leadership (e.g., Selznick, 1949; Selznick, 1957). The informal (CAS) function represents the emergent, informal adaptive actions of interacting individuals and groups (Roethlisberger and Dickson, 1939; Selznick, 1949; Tsoukas and Chia, 2002).

Such formal and informal forces have been acknowledged for many years. Frederick Taylor lamented the tendency of social forces to subvert rational processing procedures (what he called, soldiering; see Taylor's (1926) famous testimony, or chapter 2 of Marion [2002]). Selznick (1949) similarly described the relationship as a struggle between rationality (e.g., organizational goals) and irrational social forces that compromise those goals. Barnard (1938) understood that administrators function only if informal dynamics accept their leadership. Lewin (1952), perhaps foreshadowing complexity, explored ways that informal behaviors could be manipulated to create change. More recently, critical theorists, building off this early work, describe the relationship between formal and informal structures as conflictive, with elites in formal roles seeking to suppress workers in the informal dynamic (Jermier, 1998).

We, however, do not see this informal dynamic as a nuisance or as part of a conflictive struggle; rather, in the spirit of Lewin (1952), we see it as something to be nurtured and enabled. Like Lewin, we see it as a valuable force for effective change. Unlike Lewin, we do not think this force can be (or should be) managed, but rather its potential should be fostered toward the objectives of the organization (see Uhl-Bien et al., 2007, for discussion). Our approach moves beyond traditional literature in that it adopts complexity thinking to delve more deeply into the inner-workings of informal processes, and suggests that informal and formal dynamics within a bureaucracy are most effective when they are entangled as a unified dynamic (we do not isolate them as separable events as earlier researchers have done). We view informal dynamics as a valuable organizational resource, and CLT is about how to foster that resource.

To address the actions of these formal and informal dynamics and their integration, we will identify three functions of complexity leadership in bureaucratic organizations-administrative leadership, adaptive leadership, and enabling leadership-and describe these functions as entangled. Administrative leadership is the managerial form of leadership that addresses the bureaucratic functions of the organization while not stifling the complex dynamics capable of producing adaptive change (Marion \& Uhl-Bien, 2007). Adaptive leadership is an informal leadership process that occurs in intentional interactions of interdependent human agents (individuals or collectives) as they work to generate and advance novel solutions in the face of adaptive needs of the organization (cf. Heifetz and Laurie, 2001; Johannessen and Aasen, 2007). It is productive of new ideas, innovation, adaptability, and change (Uhl-Bien et al., 2007). Enabling leadership acts in the interface between the other two: it works to foster conditions conducive to the complex interactive dynamics of adaptive leadership and manages the administrative-to-adaptive and innovation-to-organization interfaces (Marion \& UhlBien, 2007). Entanglement recognizes that administrative and adaptive leadership must work together effectively if organizations are to function properly; therefore, entanglement refers to a dynamic relationship between the formal top-down, administrative forces and the informal, complexly adaptive emergent forces in organizations (cf. Thomas, Kaminska-Labbé, \& McKelvey, 2005).

These entangled functions are meso in that they inherently cross organizational levels. Moreover, they are functions they describe leadership behaviors rather than individual leaders; with the exception of administrative leadership, anybody can engage in these functions. The point in complexity leadership, then, is not so much to identify or label individuals as these types of leaders, but rather to consider complexity leadership behaviors that individuals engage in and their effects on the organizational systems and their dynamics.

A meso model illustrating the CLT framework in bureaucratic organizations is presented in Figure 1. In this model, the cone represents the bureaucratic superstructure that is the domain of the administrative function, while the CAS represent the networked informal dynamics of the adaptive function. The top of the picture shows that CAS are embedded within and permeate across the bureaucratic organizing structure (in CLT this is "entanglement"). The lower part of the picture dissects these two functions to show the three roles of CLT: administrative leadership occurs in the administrative structure, adaptive leadership in the CAS structures, and enabling in the interface between the two.

The outcomes of interest in Complexity Leadership Theory are shown at the bottom of the figure as innovation, learning, adaptability and new organizational forms. Consistent with complexity thinking, these outcomes are seen as emergent (Carley and Lee, 1998; Gryskiewicz, 1999). Emergence, according to Lichtenstein \& Plowman (2009) is often described as "qualitative novelty" in a system, or "the coming into being of a semi-autonomous 'level' of activity...that is generated out of the system's components (von Bertalanffy, 1956) yet 'transcends' them by producing outcomes that are unexpected or striking in some way" (p. 6). In Complexity Leadership Theory, emergence is proposed to be driven by the adaptive function (the interaction of adaptive leadership and CAS dynamics). For bureaucratic organizations to benefit from emergence produced by the adaptive function the outcomes must be integrated back into the formal administrative system in the form of innovations, products, services, new systems or processes, etc. (Mumford, Bedell-Avers, \& Hunter, 2008). This is one of the roles of the enabling function (i.e., the innovation-to-organization interface, Dougherty \& Hardy, 1996). Enabling leadership is also important in fostering the enabling conditions for the adaptive function (i.e., administrativeto-adaptive interface) when administrative leadership is not already doing it. 


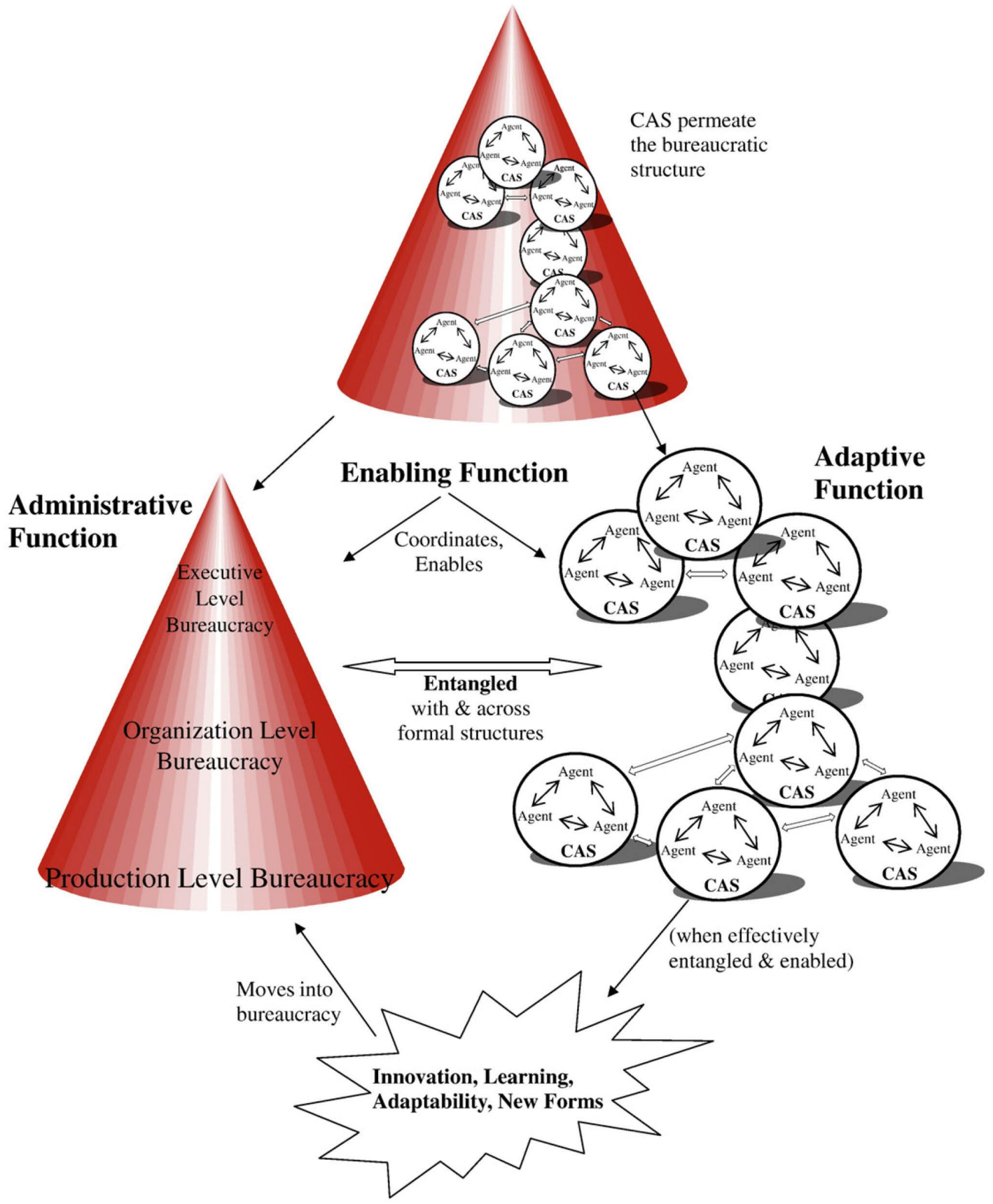

Figure 1. Meso model of Complexity Leadership Theory.

Because the concept of enabling leadership as managing in the entanglement between the administrative and adaptive function is so integral to the basic framework of complexity leadership in bureaucratic forms of organizing, we turn next to the concept of entanglement and the enabling leadership role to provide an overview of the core propositions of Complexity Leadership Theory for bureaucratic structures.

\subsection{Entanglement and the enabling leadership role}

A core premise of CLT in bureaucratic forms of organizing can be described as follows: More adaptive bureaucratic forms of organizing will have well-functioning informal leadership processes (i.e., adaptive leadership) producing innovative responses to complex problems, and these adaptive leadership processes and outcomes are effectively entangled with administrative leadership. In other words, in bureaucratic forms of organizing, complexity leadership requires effective adaptive leadership generat- 
ing emergent outcomes that are productive for the firm (Osborn \& Hunt, 2007) that is properly entangled with administrative leadership (does not stifle adaptive dynamics; Marion \& Uhl-Bien, 2007).

Proposition 1: More adaptive bureaucratic organizational structures will have well-functioning informal leadership processes (i.e., adaptive leadership) producing innovative responses to complex problems and these adaptive leadership processes and outcomes are effectively entangled with administrative leadership.

Recognizing, however, that effective entanglement is not always present, the enabling role is included in Complexity Leadership Theory. Enabling leadership operates in the interface between administrative and adaptive leadership, and the domain of enabling leadership is to help in managing entanglement. In Figure 2 we represent different scenarios with respect to entanglement and the implication of each for enabling leadership.

Quadrant A of Figure 2 represents a situation of an organization or organizational unit with highly effective entanglement. In this scenario, both administrative and adaptive leadership are operating at healthy levels relative to the organizational context and they are combining so effectively that it is hard to identify a separate enabling role or to distinguish enabling from administrative and adaptive leadership. Therefore, because administrative and adaptive are occurring at appropriate levels and are so well integrated, enabling leadership is not apparent. An example can be seen in the following description of IDEO:

IDEO is a zoo. Experts of all flavours co-mingle in offices that look more like cacophonous kindergarten classrooms. ...Walk into the offices of IDEO design in Palo Alto, California, immediately you'll be caught up in the energy, buzz, creative disarray and sheer lunacy of it all....The culture itself reflected the importance that management attached to creating a democracy of ideas... the company discouraged formal titles and did not mandate a dress code. Management encouraged employees to leave their desk and walk around, especially during mental blocks... IDEO paid high rent for its prime Silicon Valley location so as to encourage stimulating interactions between employees. Free, unlocked loaner bicycles at the Palo Alto lobbies also facilitated movement between each building. Designers were encouraged to talk to one another or even call a brainstorming session through email. (Thomke \& Nimgade, 2007, pp. 5-6).

Quadrant B of Figure 2 represents a very different kind of scenario. In this case administrative occurs at excessively high levels and adaptive is not occurring because it is being smothered by, for example, stifling control preferences of administrative leadership. For this organization, more adaptive leadership is needed for the health and fitness of the firm

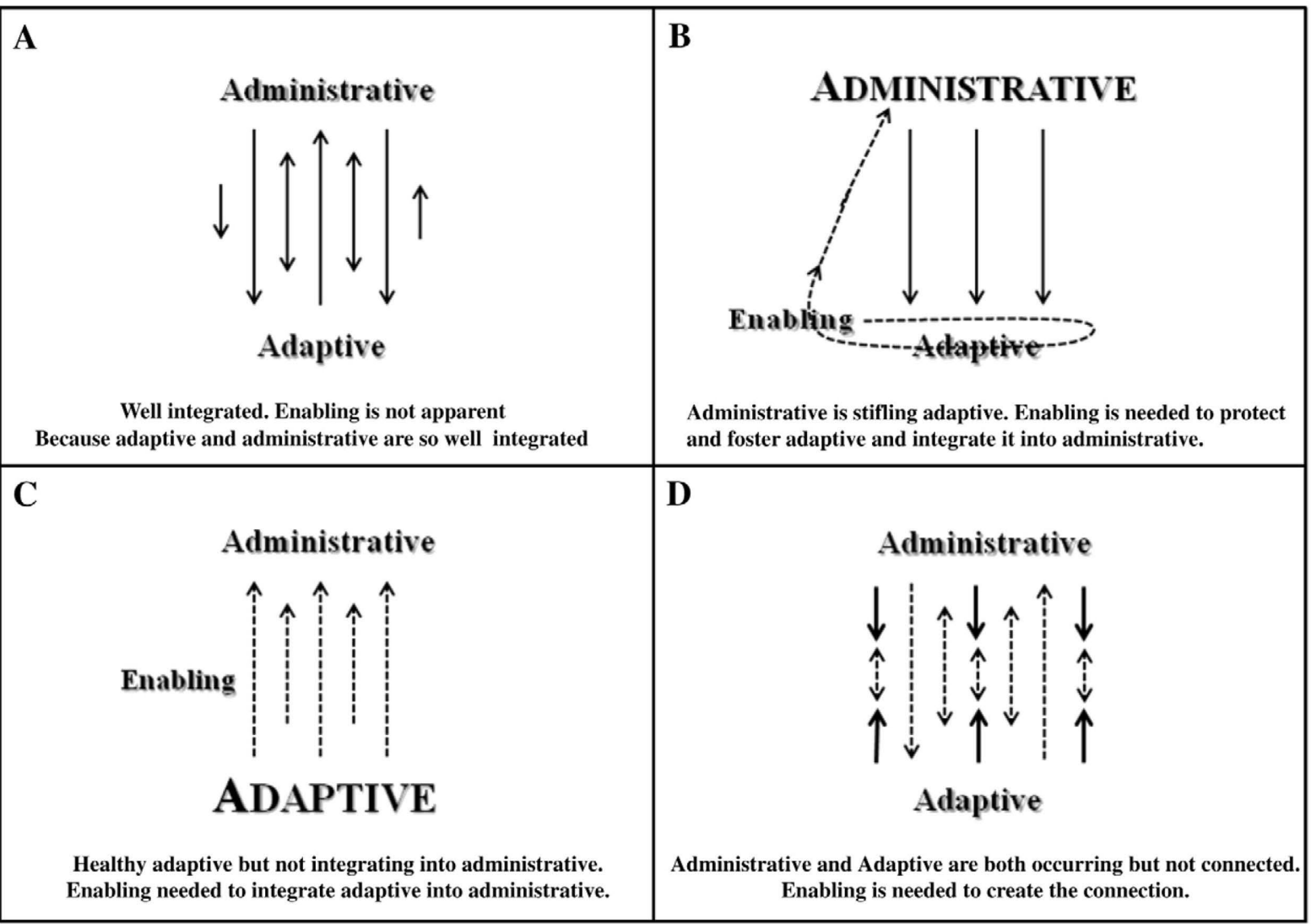

Figure 2. Entanglement and enabling leadership functions in Complexity Leadership Theory. 
but it is not occurring because of the overbearing administrative leadership function. Therefore, the role of enabling leadership (represented in Figure 2 by dotted line) is needed in two ways: a) to protect and foster conditions conducive to the emergence of effective adaptive leadership processes (i.e., administrative-to-adaptive interface) and b) to integrate the emergent outcomes generated by the emerging adaptive leadership processes back into the bureaucratic superstructure to generate adaptive outcomes for the firm (i.e., innovation-to-organization interface). For example, GE created strong enabling climates for innovation as well as effective systems for integrating this innovation back into the organizational systems/structures (McKelvey, 2008).

Quadrant C of Figure 2 is the opposite in some ways of quadrant B. In this case, adaptive leadership is not only occurring in the organization, it is thriving. However, the problem here is that the emergent outcomes being produced are not being captured by the organization and tremendous innovative and adaptive capacity is being lost. Therefore, in this scenario, the role of enabling leadership (represented by dotted line) is to integrate the innovative outcomes of adaptive leadership back into the bureaucratic and administrative system. This can be seen in the classic example of XEROX and the Palo Alto Research Center in the mid-1970s. Xerox essentially gave away the seeds of the personal computer industry developed by their Palo Alto Research Center (PARC)-a highly adaptive R\&D unit-because management did not see the value of what they had produced (Cringley, 2002).

Finally, quadrant D represents a case in which both administrative and adaptive are occurring but they are not "meeting" each other in terms of connecting. Therefore, the role of enabling is to help in making these connections between administrative and adaptive. For example, research universities have healthy research initiatives (adaptive activities) that are linked to their administrative units via such enabling functions as offices of patents or divisions of research.

These ideas can be summarized in the following propositions:

Proposition 2a: When adaptive and administrative functions are effectively entangled the role of enabling leadership will either be not apparent or hard to distinguish from the other two roles (administrative and adaptive).

Proposition 2 b: In cases where administrative is overly powerful and stifling adaptive leadership processes, the function of enabling leadership will be needed to foster and protect adaptive leadership processes and then feed the emergent outcomes of these processes back into the administrative system (to generate adaptive outcomes for the firm).

Proposition 2c: In cases where adaptive leadership is healthy and productive but innovative outcomes are not being fed back into the organization, the function of enabling leadership will be needed to integrate the innovative outcomes of adaptive leadership back into the administrative system.

Proposition 2d: In cases where administrative and adaptive leadership are both occurring but are not integrating well with one another, the function of enabling leadership will be needed to help administrative and adaptive "connect" or "flow" with one another.

Hence, central to Complexity Leadership Theory is a healthy adaptive function, at the heart of which is adaptive leadership. But what is this and where does it come from? In the next section we describe adaptive leadership as it relates to the adaptive function of CLT.

\section{The adaptive function}

A core element of Complexity Leadership Theory (CLT) is a proposed set of informal interactive dynamics that produce much of the adaptability in organizations. In CLT, this adaptive function is comprised of three main elements: adaptive leadership (an agentic function), CAS dynamics (non-agentic network forces), and enabling conditions (conditions conducive to generation of adaptive leadership and CAS dynamics). Adaptive leadership is intimately intertwined with CAS dynamics, and enabling conditions help create the contexts that are productive of adaptability, emergence and innovation.

To understand the nature of this intertwinement we need first to understand the non-agentic CAS dynamics in informal systems-what we refer to as mechanism-based theorizing-as it relates to what Streatfield (2001) called, "the paradox of control." We also need to understand the elements of the adaptive function: adaptive leadership, complexity (CAS) dynamics, and enabling conditions. Therefore, we describe each of these below.

\subsection{Level of analysis of the adaptive function: mechanisms}

As described above, complexity leadership sees the adaptive function as an emergent dynamic. In bureaucratic contexts, CLT recognizes that "a major source of organizational unpredictability comes from inside the organization - from the ongoing interaction of individuals and groups within the organization whose actions, exchanges, interactions, and adaptations to each others' actions are not controlled (or even understood) by organizational leaders" (Plowman \& Duchon, 2008, p. 138).

This unpredictability, or nonlinear behavior, is produced by meso dynamics that are called, mechanisms. Mechanismbased theorizing is a concept borrowed from sociology that helps us to move beyond some of the limitations of variablebased approaches for processual, or dynamic, theories (Davis and Marquis, 2005; Hedström and Swedberg, 1998a). Variables are more suitable for linear causal modeling and exploration of relationships among constructs rather than dynamic relationships among actors and events (Hedström \& Swedberg, 1998b). While appropriate for linear theorizing, variablebased research has limitations for nonlinear theorizing, such as complexity. 
Both complexity and mechanism-based theorizing recognize that we can't predict outcomes with certainty because too many actors interact in complex ways within social systems; i.e., error terms are extensively correlated - a serious violation of assumptions underlying linear statistics. However, this does not mean we cannot explain. The robust nature of complex systems means that we can examine how systems perform in similar ways under different conditions. We can also identify common dynamical patterns (or mechanisms) that seem to drive different dynamical events. At a basic level, we can identify general understandings concerning the conditions for complex behavior and the dynamics of complex systems (Cilliers, 1998).

Mechanism-based theorizing offers us a way to generate these understandings. With mechanisms, we look for patterns of interaction that are recognizable across situations to identify an intelligible answer to the question of why something happened in situations where specific causes and effects are not identifiable (cf. Elster, 1998). The study of mechanisms (rather than variables) focuses us on generating understanding of the dynamic processes that emerge from interaction of individuals connected together in complex adaptive systems (cf. Anderson, 1999; Davis and Marquis, 2005; Elster, 1998; Hedström and Swedberg, 1998b). In complexity leadership, for example, we would not pose the argument that certain combinations of variables predict changes in levels of innovation (also defined as a variable). Instead, we would argue that, by enabling certain conditions (e.g., dynamic interaction, interdependence, adaptive tension), one can influence mechanisms that produce the often unanticipated emergence of innovation. These CAS dynamics are predictable in their processes but unpredictable in their outcomes.

The logic of mechanisms is consistent with the null condition described in the levels literature (Dansereau, Alutto, \& Yammarino, 1984). The null condition "involves the idea that levels, including wholes, parts, and independent entities, may emerge over time from 'nothing'" (Dansereau, Yammarino, \& Kohles, 1999, p. 349). That is, one level of emergence may be independent of activities at another level. It "allows for the possibility that effects at a higher level may not be reducible to a lower level of analysis...in other words, it allows for nonreductionist views" (Dansereau et al., 1999, p. 349).

The complexity perspective agrees with this description of the null condition except in an important, and revealing, detail. The null condition argument is that order can "spontaneously generate" in a given level; complexity argues that emergence is the product of interactions and phase transition (with phase transitions being a mechanism) (Marion, 1999). That is, order is not spontaneously generated from nothing; it is generated by sudden shifts in interactive dynamics (see McKelvey, 2008 for a good discussion of this). It only seems spontaneous because it is hard to trace to causal variables. Much like synergy, complexity is not reducible to a lower level or to the individual level (Dansereau et al., 1999; Klein et al., 1994). Instead, it emerges from interactions among agents and across levels and can best be understood as products of the unpredictably changing processes that occur because of mechanisms and interactive dynamics (i.e., nonlinearity).

In complex systems, information about the relationship between cause and effect is quickly lost (Baker \& Gollub, 1990). Thus complexity does not lend itself well to approaches based on scientific laws, which state that for any given initial condition a particular cause will necessarily produce a certain, predictable effect (Elster, 1998) - a linear view (Elster, 1998). Instead, complexity focuses us on nonlinearity - the condition of small changes causing large effects or combinations of patterns resulting in new patterns that are not linear combinations of the original patterns (Cilliers, 1998; Marion, 1999). This nonlinearity makes complexity approaches better suited to mechanism-based theorizing than more traditional variable-based views (Hedström \& Swedberg, 1998a).

Some, of course, would consider this "very controversial," to use the terminology of Dansereau et al. (1999) in their discussion of null conditions. The controversy with this perspective is in the concept of irreducibility to individual parts - meaning that the higher-level entity is not merely aggregated, it is holistic (i.e., possessing limited direct relationship to its constituent parts). This creates problems for methodological individualists who, while conceding that a totality is more than the sum of the parts, refuse to concede direct causal relationships between constituents and the higher-level entity.* They will likely take exception with a perspective which argues that effects cannot be always be traced to causal roots (outcomes are not a function of initial values, or independent variables). These methodological individualists assume that outcomes are the products of the actions of individuals, and reject any notion of collectivism (see Hedström \& Swedberg, 1998b for discussion).

Despite our focus on complexity, we actually see merit in the latter claims. While the mechanism perspective is a holistic perspective, we must agree that outcomes are often influenced by individual actions as well. Consequently we adopt a "compromise" position that Hedström \& Swedberg (1998b) call a "weak form" of methodological individualism:

The weak version of methodological individualism takes the same ontological position as the strong version [that 'causal agents' are always individual actors and social science explanations should always include explicit references to the causes and consequences of their actions] but accepts for the sake of realism non-explained social phenomena as part of the explanation (pp. 11-12, emphasis added).

Complexity Leadership Theory aligns with this weak form of methodological individualism in that it acknowledges the role of individuals and agency (i.e., what we will call, adaptive leadership) but also recognizes that non-explained social phenomena are part of the explanation (i.e., CAS dynamics). It is this recognition that leads us to propose a model of adaptive functioning based on interdependent (and meso) relationships between agentic actions and emergent (mechanism-based) forces.

\subsection{The paradox of control: agentic behaviors and CAS dynamics}

This weak form of methodological individualism raises the specter of what Streatfield (2001) called, the paradox of control. Adaptive leadership is related to the human desire to control, while CAS dynamics are "uncontrollable," or emer-

* We thank an anonymous reviewer for The Leadership Quarterly for these comments. 
gent. Adaptive leadership relates to the agentic, or deliberative, nature of human activity and CAS (or mechanism driven) dynamics represent the inevitable, uncontrolled processes that emerge from complex interactive forces. Streatfield (2001) describes this as being both "in control" and "not in control" - the paradox of control.

Streatfield (2001) argues that in bureaucratic organizations, managerial contexts are emergent in that interconnected processes across an organization generate collective emergent outcomes that cannot be traced back to specific actions; these represent the reality of managers being "not in control." Within such contexts, people struggle to create meaning and maintain sense of self in the face of such uncertainty; these behaviors represent attempts to be "in control."

In Complexity Leadership Theory, we refer to these differences as agentic and emergent forces. Adaptive leadership is agentic in that it involves intentional behaviors seeking to produce a desired future or outcome. Complexity dynamics are emergent (Marion, 1999) in that they arise without cause and are not focused on future outcomes. Adaptive leadership - agentic activity - is necessarily intertwined with complexity (CAS) dynamics. In a sense, CAS and their dynamics define the boundaries and the potentials for agent behavior (e.g., the context), and it is difficult for adaptive leaders to act outside those boundaries (cf. Osborn et al., 2002). Together, adaptive leadership and CAS dynamics represent the "adaptive function" of complexity leadership - the informal, complexly adaptive emergent processes of organization (Heckscher and Donnellon, 1994; Katz and Kahn, 1978; Pfeffer, 1982; Weick, 1979).

\subsection{Adaptive leadership}

Adaptive leadership is an informal leadership process that occurs in intentional acts of interactive, interdependent human agents (individuals or collectives) as they work to generate and advance novel solutions addressing adaptive needs of the system (cf. (Heifetz \& Laurie, 2001). It engages with CAS dynamics to produce emergence (Goldstein, 2007; Lichtenstein \& Plowman, 2009-this issue), new ideas, innovation, adaptability, and change within organizations (e.g., Plowman et al., 2007; Plowman et al., 2007; Chiles et al., 2004; Hazy, 2008; Schneider and Somers, 2006).

Adaptive leadership is agentic, meaning that (a) it reflects the capacity for human beings to make choices in the world and (b) it acknowledges human behavior as producers as well as products of social systems (Hosking, 2001). It is leadership because it involves intentional, local acts of influence to create change (Bryman, 1996; Katz and Kahn, 1978) to enhance the viability of the organization (cf. Ireland \& Hitt, 1999). The agentic acts of adaptive leadership occur when people envision issues in organizations that require new learning, innovation, or new patterns of behavior (i.e., adaptive challenges, Heifetz and Laurie, 2001; Heifetz and Linsky, 2002) and engage in interactive behaviors to address these challenges, either proactively or reactively (cf. complex responsive processing; Johannessen and Aasen, 2007; Stacey, 2001).

A unique aspect of adaptive leadership relative to traditional approaches is that it is necessarily contextual (Osborn et al., 2002). Contrary to traditional perspectives that define context in terms of such things as environment, organization, technology, size and structure (Yukl, 2005), we define context as unplanned and uncontrolled mechanisms that emerge naturally among interactive, adaptive agents acting in situations. This relationship between adaptive leadership and context is not static like the relationship between leadership and technology described by Charles Perrow (1970) and other contingency theorists; rather, the relationship between adaptive leadership and context is constantly shifting and changing. Once the relationship is engaged, the parts are never again observable in their original forms (Cilliers, 1998).

Thus adaptive leadership (both individual and collective) is a dynamic process in which agentic adaptive leaders interact with-and engage the potential of-emergent complexity dynamics to produce adaptive change for an organization. Adaptive leadership involves interacting with the "complex interactive dynamic" of CAS and their mechanisms (UhlBien et al., 2007), and adaptive leaders (both individuals and collectives) must be adept at recognizing and engaging with the dynamic and complex contexts in which they operate.

\subsubsection{Adaptive leadership and information flows}

Moreover, adaptive leadership is not about directing or motivating subordinates, as in traditional conceptualizations.* Rather, adaptive leadership helps produce a rich flow of information (in the form of ideas, innovations, changes, technologies, etc.) to enhance dynamic complexity processes. This richness generates information and information flows for CAS dynamics. CAS function on, and because of, information (Cilliers, 1998).

Information flows can occur when interacting adaptive leaders (individuals and collectives) imagine and effectively advance new ideas, capabilities, opportunities and possibilities (cf. Hargadon \& Bechky, 2006) within a dynamic context of CAS. This is closely related to innovation in bureaucratic systems. As described by Chang \& Harrington (2007), key elements of innovation include: (a) the endogenous development of networks through which ideas disseminate and spread, (b) the discovery of new ideas, and (c) the observation and adoption of ideas. In other words, for innovation to occur, new ideas must be generated that have the potential to create positive change in the organization, and these ideas must then flow into the formal organizational systems and structures to create this change. Flow, or the processes through which ideas either gain momentum and eventually create innovation for the organization or do not gain momentum and die or disappear, is important because if the ideas being generated by adaptive leadership interaction do not take hold and create change then they do not constitute effective leadership (Uhl-Bien et al., 2007). Hargrave \& Van de Ven (2006) hinted at the role of adaptive leaders and information flows when they argued that leadership is:

* Adaptive leadership does not dismiss human relations, it is just that human relations is not the focus of CLT. In CLT, human relations is a valuable precondition for adaptive leadership in that interactive processes are more likely and more effective in conditions of good human relations (e.g., trust, respect, good relationships, open communication). 
... a political process in which actors contributed to a larger solution by recombining inherited practices, technologies, and institutions to address their own unique and partisan interests. In both cases the leaders of the movements displayed political savvy in understanding the interests of the other players in the network, as well as the ability to frame the change agenda in ways that appealed to the interests and identities of these other actors. (Hargrave \& Van de Ven, 2006, p. 865)

Based on the above discussion, we can propose that:

Proposition 3: Adaptive leaders (individuals or collectives) are adept at recognizing (i.e., "reading") and engaging with the complex interactive dynamic (e.g., CAS) in which they operate.

Proposition 4: Adaptive leadership helps produce a rich flow of information (in the form of ideas, stories, innovations, changes, technologies, etc.) to stimulate and enhance dynamic complexity processes.

These propositions recognize (a) cognitive processes of adaptive leaders (individuals and collectives) and (b) behaviors they engage in with respect to information flows. The first involves "seeing" (or intuitively understanding) the dynamics and the second involves "acting on" them by interacting with information flows. In the sections below we build on these basic propositions by elaborating these two (cognitive and behavioral) processes of adaptive leadership with respect to complexity dynamics.

\subsection{Complexity dynamics}

Complexity dynamics (or mechanisms) are the emergent processes through which CAS form and operate. They are often referred to as self-organizing, in that the process evolves without an external designer or the presence of some centralized form of internal control. Instead they are the result of a complex interaction of the environment, the present state of the system, and the history of the system (Cilliers, 1998). It is the capacity for self-organization that allows complex systems to develop and change their internal structure spontaneously and adaptively to cope with (or manipulate) their environment (Cilliers, 1998) -i.e., to be emergent.

As described by Boal \& Schlultz (2007), the concept of complex adaptive systems is attractive to leadership and organizational scholars because it shows that surprising and innovative behaviors can emerge from the interaction of groups of agents, seemingly without the necessity of centralized control. In the sections below we describe these processes by identifying basic elements necessary for understanding CAS dynamics and discussing their significance for adaptive leadership.

\subsubsection{Nonlinearity}

Perhaps the most fundamental element to understanding CAS and their dynamics is the concept of nonlinearity. Nonlinearity means that a change in a causal agent does not necessarily elicit a proportional change in another agent. In contrast to simple (linear) models of causality that predict that A leads to B, in nonlinear dynamics A may elicit no response in B, dramatic response, or a response that interacts with other factors in ways that were not predictable $a$ priori (Marion, 1999). For example, in the Iraq war the notions of being "greeted as liberators" and "mission accomplished" represented linear thinking, whereas the reality of the interactive dynamics that occurred was nonlinear (and some would say predictable in their dynamics but not their specific outcomes). As described by Greenwood \& Hinings (1996), to properly understand organizational change one must allow for nonlinear processes that generate emergence and surprise, taking into account ramifications and implications beyond those initially imagined or planned (Tsoukas \& Chia, 2002).

Nonlinearity comes from the rich interconnections that define complex systems. These interconnections are characterized by recurrency in feedback loops among the interacting element of the system. Recurrency means that any activity can feed back onto itself (sometimes directly, sometimes after a number of intervening stages) in ways that are positive (enhancing, stimulating) or negative (detracting, inhibiting); in complex systems both kinds are necessary (Cilliers, 1998).

Recurrency (i.e., nonlinearity) is part of the reason why history matters (Boal and Schlultz, 2007; Hunt and Dodge, 2000; Osborn et al., 2002) in complex systems - because the past is co-responsible for present behavior. In addition, the future must also be considered. As described by Cilliers (1998), "it remains impossible to think in the present without considering the past-or the future" (p. 122). Hence, nonlinearity also means that the study of complexity leadership must incorporate consideration of time (Boal \& Schlultz, 2007; cf. Clark, 1985; Bluedorn and Jaussi, in press).

Consistent with this, Boal \& Schlultz (2007) describe a role of leaders as connecting the past, present and future through storytelling, which acts as a "reference signal" in the recurrent feedback loops and helps guide adaptation in the system. Such behaviors also serve as information flows that offer a source of interconnectedness among organizational agents and provide a structure for knowledge flows across the organizational system (Boal \& Schlultz, 2007). Neustadt \& May (1986) describe this as "thinking in timestreams" - looking at an issue in the present with a sense of the past and an awareness of the future (see also Schon, 1983). Tsoukas \& Hatch (2001, p. 1006) cite an example of George Marshall's "acute sense of history which, while informing his decisions at a point in time, made Marshall focus his eyes 'not only to the coming year but well beyond. ... By looking back, Marshall looked ahead, identifying what was worthwhile to preserve from the past and carry into the future' (Neustadt \& May, 1986: 248)." 
Recurrency and nonlinearity are also part of the reason Osborn et al. (2002) address the importance of a leader's role in the patterning of attention. As they describe, patterning of attention involves isolating and communicating what information is important in an endless stream of events, actions and outcomes. It calls on leaders to separate what is more important in the system from what is less important-i.e., what to pay attention to in the face of complex and dynamic uncertainty.

Hence, linked to our adaptive leadership propositions above, we can propose that:

Proposition 5a: Adaptive leaders (individuals or collectives) are more adept at "reading" complex dynamics in which they operate by engaging in nonlinear thinking (e.g., systems thinking, thinking in timestreams, patterning of attention) rather than linear thinking.

Proposition 5b: Adaptive leaders (individuals or collectives) foster information flow and structure organizational knowledge flows by engaging in dialogue that help connect past, present and future (e.g., dialogue conveying history, storytelling).

\subsubsection{Bonding}

A second key element for understanding CAS and their dynamics is a concept we will call bonding. This concept is a function of the network dynamics of CAS (CAS are network structures). Bonding is the "linking up" dynamic through which CAS networks form and evolve. It occurs through processes of interaction and aggregation, and serves as the "vehicle" for emergence. Bonding is dynamic in that linkages continually form and disappear as complex systems take on different shapes and forms in relation to their environments.

Bonding begins with interaction between agents (the smallest interactive unit of interest; it may be a person, group, idea, worldview, etc.). It occurs when interaction causes agents to become linked by need, preferences, outlooks, responsibilities, etc. Bonded agents act with some degree of synchrony-each agent's actions influence the behavior of the other. Interestingly, bonding need not be cooperative and can even be conflictive (e.g., competitive relationships); the basis for bonding is only that the participants function together in a way that creates interdependent actions.

Bonded pairs are the foundation of aggregates, and the moment a pair bond becomes a multiple bonding, the dynamics of the relationship change (Krackhardt \& Kilduff, 2002). Aggregated agents form alliances, they shift allegiances, and they change relative to one another in unpredictable ways-i.e., they become CAS. CAS agents are interdependent and at times such interdependencies are conflictive in that the goals of one are thwarted by the goals of another. This is a conflicting constraint, and a network of such constraints pressure the system to elaborate and change its structure or preferences.

A CAS, or a system of CAS (what Marion \& Uhl-Bien, 2001 called, a meta-meta aggregate) is maximally adaptive when such pressures (in conjunction with other pressures) push it to a level at which the system is teetering on the edge of too much pressure-a bit more and it may devolve into chaos. Even so, it functions quite productively and adaptively here at the edge of chaos. And on occasion parts of the system (and on rare occasion, the whole system) do indeed totter over the edge and experience chaotic phase transitions, or shifts of form or preferences into new form or preferences, as the USSR did in 1989. This is the essence of change in complex systems, and phase transitions occur at all levels of intensity from very small changes to major ones. Elaboration in response to pressure is a wellspring of adaptability; phase transitions are a wellspring of adaptability and innovation in organizations.

It is this dynamic with which adaptive leadership interacts. Adaptive leaders see these interconnections and tend to have a keen sense of timing when they act. Adaptive leaders foster information flows by building their personal networks of interconnectivity and interdependencies. By their actions, they inject ideas and information into the system for it to mull and process. Adaptive leaders embrace diversity and are comfortable with divergent or conflicting ideas.

Hence, linked to our adaptive leadership propositions above, we can propose that:

Proposition 6a: Adaptive leaders (individuals or collectives) are adept at "reading" complex dynamics in which they operate by seeing interconnections and having a keen sense of timing (e.g., with respect to potential for phase transitions).

Proposition 6b: Adaptive leaders (individuals or collectives) help stimulate and enhance dynamic complexity processes by injecting information and ideas and by fostering interconnectivity and creating linkages.

\subsubsection{Attractors}

A third element of complexity dynamics is the concept of attractors. Attractors are "phenomena that arise when small stimuli and probes (whether from leaders or others) resonate with people. As attractors gain momentum, they provide structure and coherence" to a system (Snowden \& Boone, 2007, p. 6). An attractor is a dynamic, a trajectory of behaviors, a gravity pit that draws people into it and influences their behaviors. The phenomena that define a fad are an attractor, for example. The essence of institutional theory (DiMaggio \& Powell, 1983)-the attraction to socially defined, isomorphic preferences for acting or organizing-is also an attractor. In a sense, a CAS is an attractor, a dynamic that influences behaviors.

Attractors are illustrated in complexity science with the concept of the "fitness landscape." The fitness landscape is a malleable landscape of peaks representing fitness strategies, but is best understood if one inverts the peak landscape into one with depressions (as Snowden (2008) did in his investigation of political attitudes in third world countries). Depressions in the landscape represent fitness attractors: the deeper the depression, the more fit the system and the more powerful the attractor. A nascent system will "search" a landscape, bouncing in and out of depressions, until it finds one deep enough to serve it and deep enough that it can't bounce out easily (Carley \& Svoboda, 1996). Searches are largely blind because agents typically have limited knowledge of an attractor's potential before hand. From an attractor perspective, the system is seeking an attractor strong enough to hold it. 
For example, in traditional change leadership models it is assumed that "movement" is generated by the "leader"-the person occupying the hierarchical role-and by the direction he or she sets (Conger \& Kanungo, 1998). However, what we know from practice is that hierarchical leaders are not always successful in creating the movement they want. The concept of attractors may help explain this. Mature organizations are "trapped" by the fitness attractor that defines them and consequently can be difficult to change. "Trapped" can be understood in two senses: First, it suggests that the system is committed to, for example, a technology (i.e., production outcomes, Aldrich, 1979) which produces outcomes that successfully sustain it, and changing that technology (moving peremptorily to another attractor) would be hazardous (Arthur, 1989). Second, once a system is captured by a given attractor, it becomes interdependent with other systems in that attractor, interdependent in the sense that they depend on one another. Attempts by an agent to unilaterally pull out of such interdependencies may be resisted by other agents in the attractor that have grown to depend upon that person (Arthur, 1989). Agentic actors, then, face daunting obstacles when attempting to change a system.

Effective adaptive leaders are aware of the potential of such dynamic behaviors (even if they are not conversant with complexity theory) and work to enhance their potential. As stated earlier, adaptive leaders see interconnections and tend to have a keen sense of timing that guides their actions. Adaptive leaders even act as tags - a stimulus that fosters the emergence of attractor dynamics (see Holland, 1995, for discussion of tags; there are numerous historical actors who have served in this role, e.g., Martin Luther King, Winston Churchill, Franklin Roosevelt; see Marion, 1999).

Moreover, while administrative leaders, agents with authority, can sometimes overcome such resistance (although this can be difficult and fraught with hazards; e.g., Pepsi-Cola's effort to change its popular soft drink's formulation in the 1990s), adaptive leaders do not act from such authority. Nonetheless, they are powerful agents of change (perhaps more powerful than administrative leaders), assuming the timing and complex forces are present. In the right conditions, adaptive leaders can inject information into the system, propose stimulating new ideas, and springboard off of diversity and divergence to enhance the magnetic appeal of attractors. Adaptive leaders can also stimulate network dynamics such that their actions can maintain the system at the edge of chaos. Such dynamism creates numerous adaptive phase transitions, some of which can be quite massive (e.g., see Marion's discussion of the microcomputer revolution, 1999).

Hence, linked to our adaptive leadership propositions above, we can propose that:

Proposition 7a: Adaptive leaders (individuals or collectives) are adept at "reading" complex dynamics in which they operate by recognizing attractors and understanding the nature of the movements they create.

Proposition 7b: Adaptive leaders (individuals and collectives) help create information flows that stimulate the emergence, or enhance the attractiveness, of attractors.

\subsection{Enabling conditions}

We stated earlier that the study of complexity involves both an understanding of the dynamics of complex systems and the conditions under which complex behavior occur. Therefore, we turn next to a discussion of these conditions. We call them enabling conditions because, when present, they enable the emergence of complex behavior and dynamics (cf. Smith \& Graetz, 2006).

\subsubsection{Dynamic interaction}

As described by Cilliers (1998), in order to constitute a complex system the elements have to interact and the interaction must be dynamic. This means that the interactions must have emergent properties that are not fixed. If they are fixed they are not able to shift and emerge (a prerequisite for complex systems, Cilliers, 1998). Therefore, a necessary condition for complex behavior is interaction, and more precisely, dynamic interaction.

Dynamic interaction is essential for, and productive of, the nonlinearity, coupling, and attractor dynamics described above. It is because of dynamic interactions that complex systems change and evolve over time. Such interactions cannot be overly defined or controlled, or they will be predictable rather than dynamic and emergent (i.e., generating "newness"); they will be linear rather than nonlinear. Moreover, these interactions are not just interpersonal-they include such things as informational (e.g., ideas, knowledge, learning, worldviews) and physical (e.g., technology, resources) exchanges.

Dynamic interaction, indeed the entire adaptive process, largely involves local processes (Cilliers, 1998). By local we mean that individuals within a system respond more to immediate needs, preferences, pressures, conflicts, and information, largely because this is the information to which they are privy or that affects them directly. That is, decision-making in a complex system is driven more by local need than by systemic need. The give and take of interacting local needs in a complex network can foster cooperation more than competition: Agents who depend on one another must compromise and cooperate in order to achieve their personal goals. In this process, people share ideas and knowledge, different bits of knowledge and ideas merge, diverge, and elaborate. The net outcome is learning, adaptability, innovation, and new order.

Recent work on collective creativity and reflexivity helps illuminate the concept of local and dynamic interaction. Drawing from theory on collective mind (Weick \& Roberts, 1993) and interactionist models of individual creativity (Woodman, Sawyer, \& Griffin, 1993; see also Drazin, Glynn, Kazanjian, 1999), Hargadon \& Bechky (2006) describe collective creativity as a process through which one person's actions or comments shape the others' action and comments, which in turn (when heeded) shapes the next. Collective creativity emerges not within a single individual but rather in insights that emerge in the interactions between individuals - where no individual insight is by itself responsible for solv- 
ing a given problem. It recognizes that "one person's past thinking and action take[s] on new meanings-to everyone involved-in the evolving context of subsequent thinking and action" (Hargadon \& Bechky, 2006), pp. 486-487).

The concept of reflexivity also helps illuminate this dynamic. Reflexivity (Tsoukas \& Chia, 2002) refers to the generation of new descriptions (new understandings) that result from human's ability to be reflexive in the context of interactions with one's own thoughts and the thoughts of others. Through reflexivity people draw new distinctions, imagine new things, and employ metaphor and mental imagery while being mindful of earlier patterns of actions. "In this view, actors are conceived as webs of beliefs and habits of action that keep reweaving (and thus altering) as they try to coherently accommodate new experiences, which come from new interactions over time" (p. 575).

Hence, dynamic interaction provides the context in which the adaptive function operates - it is a necessary condition for adaptive leadership and CAS dynamics.

Proposition 8: The adaptive function of CAS requires conditions that allow for dynamic interaction (i.e., fostering dynamic interaction enables greater complex adaptive behavior).

\subsubsection{Interdependence}

Another necessary condition for complex dynamics is interdependence. In complexity theory interdependence is associated with the concept of shared need (Marion \& Uhl-Bien, 2001), which refers to the extent to which individuals interact to accomplish a task, goal, objective, vision, etc. Without interdependence, agents will not be likely to engage in the dynamic interaction and bonding behavior necessary in complex adaptive systems.

Shared need is different from traditional leadership approaches that focus on a "shared goal" or "vision" in that it does not require agents to hold the same goal or vision. Rather, it recognizes that in collaborative efforts, partners often do not share the exact same goals but instead have personal needs that can best be satisfied by working together. For example, in business partnerships, one partner may be working toward a need to get rich while another partner may be working to change the world. In academic writing collaborations, a senior scholar may be motivated to advance knowledge while a junior scholar may be motivated to get tenure. In these examples the goals are not inconsistent, but nor are they the same; they do not represent a shared goal in the sense that they are striving for the same personal outcomes, but they do represent a common need to work together to achieve their personal goals (i.e., they represent an interdependence).

While the difference between shared need and shared vision (goal) may appear subtle, the implication is not: it suggests that, in leadership, focusing attention on getting alignment around a shared vision or goal may be a waste of time or even undesirable (it may dampen creativity by fostering homogeneity over heterogeneity). It suggests that interdependence is a more powerful force for change than alignment around a "single" vision (or shared goal). The implication of shared vision suggests "changing" someone's needs to match the leader's vision - a task that becomes quite lofty, and often unattainable, in reality. Shared need instead starts with the "what's in it for me?" question and whether it is advantageous to work together to accomplish personal goals; it understands that if interdependence is not inherent or acknowledged, the likelihood of fully engaging others is slim.

In this way, Complexity Leadership Theory recognizes the powerful motivating force of interdependence. If interdependence is not felt, complex adaptive behavior will likely not occur because individuals will not be motivated to engage. This is not trivial and may explain why so many change efforts or efforts at coordinating multi-team systems (Mathieu, Marks, \& Zaccaro, 2001) report problems of energizing participants around the core mission/vision: they don't feel connected to (i.e., interdependent with) that vision or they don't really share the goal. In nature, agents that are not interdependent would not belong to the system. However in social systems, organizing frameworks often create "artificial" interdependencies in that individuals are placed in systems to which they may feel little personal attachment to (interdependence) or engagement with the system goal.

Thus, interdependence is critical in motivating dynamic interaction in CAS. When individuals feel greater interdependence they will be more likely to engage in complex adaptive behavior. It also means that if managers (leaders) want to create conditions that enable complex behavior they need to foster interdependencies among agents in the system.

Proposition 9a: The adaptive function of CAS requires conditions of interdependence (i.e., fostering interdependence enables greater complex adaptive behavior).

Proposition 9b: The motivation of individuals to commit to engaging in complex adaptive behavior is proportionally related to the extent to which they feel interdependent with the system (i.e., the higher the interdependence the more motivated they are to engage in complex adaptive behavior).

\subsubsection{Heterogeneity}

Complex systems require heterogeneity. Heterogeneity refers to differences in both human and physical agents, including different skill sets, preferences, information, technology, techniques, or worldviews. It is important to complex behavior because it feeds the bonding and nonlinearity dynamics of complexity. It contributes to bonding by creating the conflicting constraints that cause agents to have to work through differences and inter-resonate in ways that produce new worldviews and innovative (nonlinear) responses (Sutton, 2002). It fosters adaptive tension by pressuring the system to elaborate - to work through conflicting constraints.

Without heterogeneity and the tension that comes from it, individuals hold the same worldviews/perspectives and are comfortable with their similarities; this restricts their ability and motivation to see in new or different ways. Nemeth \& Ormiston (2007) illustrate this idea with their test of differences in idea generation and creativity in groups where membership was stable and maintained cohesion and morale through comfort and shared experiences, versus groups that changed membership in ways that stimulated dissent, debate, and thought diversity. They found that "maintaining 
membership increases comfort and also the perception of creativity but not actual creative behavior whereas changing membership results in a less comfortable experience but also an increase in the number and creativity of the ideas generated" (p. 524). Therefore, complexity theory suggests that appropriate amounts of heterogeneity in terms of thought diversity and exposure to ideological differences is conducive to adaptive behavior (Kauffman, 1993; Kauffman, 1995; cf. Baer and Oldham, 2006; Gregory, 2006; Leung et al., 2008).

Proposition 10: The adaptive function of CAS requires conditions of heterogeneity (i.e., fostering appropriate amounts of heterogeneity enables greater complex adaptive behavior).

\subsection{Adaptive tension}

Finally, adaptive tension is a pressure on a system to elaborate and adjust. Without such pressure, there is no initiative to change. Tension can derive from various sources, including conflicting constraints, administrative leader pressure, environment (e.g., competitors), or adaptive challenges. As described above, tension from conflicting constraints often comes from heterogeneity. Moreover, adaptive challenges (Heifetz \& Laurie, 2001) create tension in that they pressure a system to create something new, to adapt in an unexpected way, or to change relationships or structures in order to meet the challenge.

A key element of complexity leadership that differs from traditional views, then, is the importance of injecting pressure (adaptive tension) on a system. Adaptive tension is not prescriptive; rather it raises challenges to which agents must adapt. Adaptive tension exerts an effect that is similar to that of the adaptive leader who injects stimulating information, except that in this case the injection is in the form of pressure to elaborate. The intent is to foster complex problem solving across networks of agents rather than to force compliance with a singular perspective.

Proposition 11: Adaptive tension contributes to the adaptive function of CAS by pressuring the system to elaborate.

\subsection{Summary}

In sum, adaptive leadership represents the human desire to predict and control, while CAS dynamics are emergent properties of complex systems. Each influences, and is influenced by, the other (see Figure 3). Adaptive leadership is an agentic influence and sense-making process that originates in struggles among individuals or collectives as they engage in meaning-making or problem solving under conditions of ambiguity or adaptive pressures (e.g., conflicting needs, ideas, or preferences) and complex dynamics. It results in (or contributes to) movements, cooperative efforts, and alliances of people, ideas, or technologies (Marion and Uhl-Bien, 2001; Marion and Uhl-Bien, 2003; Schneider and Somers, 2006).

Complexity dynamics are self-organizing processes that govern the behaviors of agents in CAS and that interact with adaptive leadership to produce emergent outcomes. CAS and their dynamics add significant capacity to a system, well over and above what the deliberative actions of individuals can offer. CAS dynamics enable networked problem solving and idea generation, the ability to adapt to conditions that are well beyond the capacity of individuals to effectively grasp (Marion \& Uhl-Bien, 2007), and the refinement of ideas (i.e., fitness landscape searches described earlier) within those complex conditions (Kauffman, 1995).

Taken together, the agentic behaviors of adaptive leaders (leadership) entwined with the emergent dynamics of complexity (context) describe the adaptive function (and contextual nature) of Complexity Leadership Theory. The adaptive function is fostered when enabling conditions (e.g., dynamic interaction, heterogeneity, interdependence, adaptive tension) are appropriately tuned for the optimal functioning of complexity dynamics (e.g., nonlinearity, coupling, and attractors) and adaptive leadership behaviors. It occurs more effectively when adaptive leadership coordinates with complexity dynamics.

Proposition 12: The adaptive function of complexity leadership is strengthened when adaptive leadership occurs under appropriate enabling conditions and its behaviors are shaped in accordance with complexity dynamics.

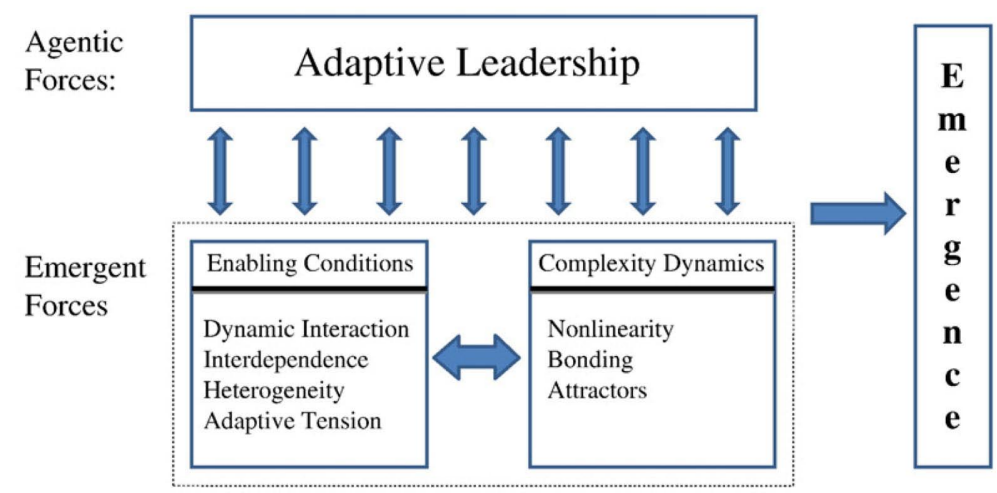

Figure 3. The adaptive function. 
It is this potential that is the ultimate focus of Complexity Leadership Theory. CLT recognizes that while agentic decisions may influence CAS dynamics or control some elements of their outcomes, they cannot replace or deny them. As we have alluded, complexity leadership (all three functions) can exert a rather significant effect on CAS dynamics, but that impact can be maximized if done skillfully with respect to the complex systems dynamics involved. As noted by Lincoln (1982), "informal networks are indispensable to organizational functioning, and managers must learn to manipulate them..." (p.11, as quoted in Nickerson \& Zenger, 2002, p. 551). Therefore, we turn next to the role of administrative and enabling leadership in CLT.

\section{The administrative (and enabling) functions}

As described above, Complexity Leadership Theory (CLT) in bureaucratic forms of organizing is based on a core proposition that appropriate adaptability occurs when the administrative function is effectively "entangled" with the adaptive function. When formal and informal are not entangled and the informal resources are not capitalized upon, the enabling function is needed (see discussion of Figure 2).

The core element of CLT, then, is a proposed set of informal interactive dynamics that produce much of the adaptability in organizations (i.e., adaptive leadership, CAS dynamics or mechanisms, enabling conditions) (see discussion of the adaptive function). These dynamics are inherently meso (cf. Anderson, 1999) in that they begin with bonding and dynamic interaction at the micro level and elaborate into aggregates at a more macro level (Marion \& Uhl-Bien, 2001). In other words, the micro dynamics (e.g., dynamic interaction and bonding) shape the nature and form of macro dynamics (e.g., aggregation), and in turn, macro dynamics shape the nature of future bonding that may occur. These dynamics are also meso in that the mechanisms, information flows and network structures of the adaptive function cross organizational levels in bureaucratic organizational forms. These inherently meso processes engage not only adaptive leadership (as already described) but also administrative (and, if necessary, enabling) leadership.

A key problem in many organizations, however, is that these meso dynamics are stifled or suppressed rather than nurtured and guided. Moreover, traditional leadership theory does not discuss the need to engage these dynamics or how to effectively interact with them with respect to change processes. Therefore, in this section we bring our discussion full circle by describing how the administrative and enabling functions can act in accordance with the meso dynamics of the adaptive function and contribute to adaptability and change for the bureaucratic organization.

\subsection{The administrative function}

A key distinction between CLT and other change models of leadership is that CLT does not view change as only, or even primarily, top-down; it does not see change as being "led" in the traditional sense of the word. Rather, a core premise of CLT is that change is emergent, unpredictable, and essentially "uncontrollable." Rather than "leading" change, in CLT administrative managers design appropriate meso contexts in the form of systems, structures and policies that allow for rich information (and resource) flows across levels to effectively engage change dynamics (the adaptive function) (Marion \& Uhl-Bien, 2007).

Rich meso contexts and information flows nurture and stimulate CAS activities and help integrate the emergent products of CAS back into organizational structures and systems. Such information flows require that heterogeneous agents (people, ideas, resources, information) be able to dynamically interact under conditions of interdependence and adaptive tension, and that they have access to administrative structures (or leaders) who can help identify and incorporate the most promising adaptive outcomes into the formal organizational system.

CLT explains why overly bureaucratic structures and centralized controls are detrimental to innovation - it is because these activities work against meso interactive dynamics (Marion and Uhl-Bien, 2007; Snowden and Boone, 2007, November). For example, in CLT, administrative leadership would not isolate workers into individual spaces or confine their functions with strict definitions, as these would act to suppress dynamic interaction, bonding, and aggregation. Likewise, CLT recognizes that too many bureaucratic rules suppress the emergence of bottom-up, interactive, spontaneous processes and meso network flows that are foundational to the adaptive function. Moreover, control and power suppress the adaptive function because they reduce heterogeneity by limiting the flow of ideas in favor of those in power (Cilliers, 1998; Jermier, 1998), with the result being no more innovative or adaptive than the person(s) in power are, alone, capable of (McKelvey, 2008; see also Heckscher, 1994).

Administrative leadership also recognizes the value and potential of adaptive leadership and rewards individuals and collectives who engage in it. It does not see this behavior as threatening to status, disobedient, or disruptive. Rather, it recognizes that adaptive leadership allows for human and social capital to be converted to intellectual capital for the firm. Administrative leadership therefore actively recruits adaptive leadership talent, develops this talent, and works to engage and retain it.

Proposition 13a: In adaptive organizations, administrative leaders design appropriate meso contexts in the form of systems, structures and policies that foster the enabling conditions for the adaptive function (dynamic interaction, interdependence, heterogeneity, adaptive tension).

Proposition 13b: In adaptive organizations, administrative leadership recognizes and rewards the value and activities of adaptive leadership (individuals and collectives).

\subsubsection{Leading change}

CLT also has strong implications for the role of the administrative function in leading change. In addition to creating meso contexts appropriate to emergence and adaptability that promote ongoing change, the concepts of attractors, local 
visions and adaptive tension offer unique perspectives of leading larger systemic change that, in some cases, are contrary to existing views.

For example, attractors offer a valuable means for understanding both resistance to change and failed change efforts. In organizations, there are people and groups who are deeply embedded within a given fitness strategy or attractor-for these individuals changing to another fitness landscape will be extremely difficult (if not impossible) (Snowden, 2008). A more feasible strategy is to target people and groups who are not so deep in a landscape to see if it is possible to gain enough momentum to attract to a new plateau (Snowden, 2008). Administrative leaders also need to watch for activities that can become "counter" attractors, drawing movement away from desired directions. When this happens they may try to stop the flow of movement toward these attractors (e.g., by extinguishing the attractor or diverting resources from it).

This relates, of course, to the question of how to manage unplanned, adaptive innovation. When the administrative structure is not conducive to the adaptive function, adaptive leadership may take on a form like Hargrave \& Van de Ven's (2006) collective action model for institutional innovation in which change emerges unbidden from "a dialectical process in which opposing actors in the organizational field frame issues and construct networks in an attempt to introduce new institutional arrangements" (2006, p. 865). Because individuals and groups do not have the support of the administrative function (e.g., resources, power, legitimacy) they engage in "a 'grassroots' form of organizing networks to build their coalition" and ally "themselves with other activists and groups with complementary interests and resources" (Hargrave \& Van de Ven, 2006, p. 865). While these efforts may be beneficial, they may also be counterproductive. As noted by Durand \& Calori (2006, p. 108), "practically wise powerful agents are more likely to conduct evolutionary changes (process). However, if their strategic analysis is erroneous, an evolutionary process of change may not enhance the firm's potential to survive." Leaders can address these issues by helping shape the emergence of desired attractors through judiciously injecting information or tension that focuses the system on strategies that are consistent with the mission of the organization. Even more directly, administrative leadership might organize periodic meetings for reviewing emerging projects to assure that they are consistent with organizational mission.

The concept of "local" in terms of dynamic interaction also has implications for vision. Local means that agents in complex systems are ignorant of the behavior of the system as a whole and can only act based on the (limited) information available to them locally (Cilliers, 1998; cf. Hargrave and Van de Ven, 2006; Nag et al., 2007). Local vision implies that administrative leaders need to share information broadly so that key decision-making criteria are available at the local levels in which adaptive leaders act. For example, Meyerson \& Scully (1995) describe tempered radicals (change agents who challenge the status quo) as acting based on local visions - they do not have broad visions of change in mind. Tsoukas \& Chia (2002) describe human agency as having a local or situated character, such that local visions are what drive local and, subsequently, organizational change.

Finally, change is fostered by adaptive tension, and administrative leadership plays important roles in generating such tension. Adaptive tension is pressure on a system to elaborate and adjust; without such pressure, there is no initiative to change. A classic and oft cited example of adaptive tension is Jack Welch's expectation at GE that its products be $\# 1$ or \#2 in the world or those projects would be deleted. But is this adaptive pressure? An earlier reviewer of our work observed that Welch's pressure was more a 38 to the head than adaptive tension. If tension is too intense, as in the above reviewer's evaluation of Welch's demands, then the tension may be counterproductive by over-stressing employees or forcing compliance with, and dependence upon, administrative control. If properly balanced, however, tension pressures people to adapt. Microsoft, for example, requires programmers to periodically synchronize their work to make sure their codes fit with one another (Cusumano, 2001): this is adaptive pressure in that it forces adaptation, but it is not pressure that overwhelms.

Proposition 13c: In adaptive organizations, administrative leaders "lead" change by engaging with attractors, nurturing local visions, and injecting appropriate levels of adaptive tension.

\subsection{The enabling function}

CLT is also unique in its addition of enabling leadership to leadership theory. As described in Marion \& Uhl-Bien (2007), enabling leadership serves two roles: it fosters conditions that enable the emergence of complexity dynamics and adaptive leadership within an organization; and it mediates the relationship between the administrative structure (bureaucratic system) and the complex interactive dynamics of the adaptive function. It does this by trying to assure a healthy ambiance for the adaptive function while simultaneously trying to assure that the adaptive function serves the goals and mission created by administrative leadership.

For example, enabling leadership helps in the administrative-to-adaptive interface by protecting the adaptive function from stifling control preferences of administrative leadership and by bringing together the enabling conditions and adaptive leadership necessary for the adaptive function to occur (Marion \& Uhl-Bien, 2007). Enabling leadership protects the adaptive function from crises that may derail adaptability - such as financial crises that threaten to withdraw resources from adaptive processes (such as R\&D). These enabling forces protect the system from political behaviors that would threaten adaptive processes, such as conflicts in which one party tries to reduce the influence of another by hampering the opposing party's initiatives. Enabling leadership can also foster pockets of enabling conditions when administrative contexts are not conducive to adaptability. It can protect the adaptive dynamic from suppressive rules, overly specific missions, micro-managing, personnel reassignments, unsupportive policy changes, oppressive pressure, and over-planning - all of which compromise the effectiveness of adaptive processes.

Enabling leaders can also help manage the innovation-to-organization interface by helping champion ideas produced by the adaptive function and bringing them to the attention of administrative leaders who can recognize and validate their potential through formalization (e.g., providing resources, incorporating initiatives into strategic plans, assigning 
work units to further develop initiatives) (Day, 1994; Howell and Higgins, 1990; Markham, 2000). Enabling leaders may do this is by acting as what Dutton \& Ashford (1993) call "issue selling." Those who engage in issue selling help ideas become integrated into the formal systems and structures of the organization:

An issue-selling perspective directs attention to the often unnoticed acts of change agents, below or outside organizations' top management groups, who invite consideration of some issues and not others. This perspective frames people outside the top management team as potentially potent initiators of change (e.g., Floyd and Wooldridge, 2000; Nonaka, 1994; Stumpf and Mullen, 1992). It helps to rewrite change as a more emergent and pluralistic process than it is typically assumed to be in more traditional "upper echelons" perspectives (e.g., Finkelstein and Hambrick, 1996; Hambrick, 1989; Hambrick and Mason, 1984). (Dutton et al., 2001, p. 717)

Proposition 14a: In adaptive organizations that are not effectively entangled, enabling leadership acts in the administrative-to-adaptive interface by protecting from stifling control preferences and political behaviors of administrative leadership that threaten adaptive processes, and by creating enabling conditions where needed and not present.

Proposition 14b: In adaptive organizations that are not effectively entangled, enabling leadership acts in the innovation-to-organization interface by activities such as championing and issue selling.

\section{Conclusion}

As described by Nickerson \& Zenger (2002), organization theory has long recognized the central role of the informal organization in bureaucratic structures for defining how work is performed and tasks are accomplished (Roethlisberger and Dickson, 1939; Crozier, 1964; Trist and Bamforth, 1951). The distinction between formal and informal organization is important because it acknowledges that while formal structures are often seen as the "blueprint for behavior" (Scott, 1981, p. 82 as cited in Nickerson \& Zenger, 2002, p. 551), the informal organization is the actual behavior of organizational members. As Nickerson \& Zenger (2002, p. 551) quote from Roethlisberger \& Dickson (1939, p. 559):

Many of the actually existing patterns of human interactions have no representation in the formal organization at all and these are inadequately represented by the formal organization. ...Too often it is assumed that the organization of a company corresponds to a blueprint plan or organization chart. Actually it never does." [emphasis added]

Despite this recognition and the fact that the informal organization is well accepted in organization studies (Katz and Kahn, 1978; Selznick, 1949), leadership research has, until recently, focused almost entirely on the formal side of the organization (i.e., leadership activities of individuals in hierarchical or formal managerial roles) and largely ignored the informal side of organizational leadership:

... [A] whole set of informal systems and relationships is essential if a bureaucracy is to work at all. ... But these informal systems are 'hidden' as it were. ... The art of 'leadership' in a bureaucracy is largely a matter of understanding these subterranean processes - 'how things really work around here' - and turn them toward support of collective goals. Nevertheless, this domain - the world of lateral connections beyond a single manager's authority-remains detached from the formal control systems of bureaucracy. ... [C]ompared to the steady development and learning about bureaucratic structures, this realm remains stunted, with little cumulative learning (Heckscher \& Donnellon, 1994, pp. 21-22). [emphasis added]

Complexity Leadership Theory as applied to bureaucratic forms of organizing helps to address this gap in understanding regarding the informal workings of organization and its relationship with the formal control systems of bureaucracy by offering a perspective of organizational leadership that recognizes the necessarily intertwined and meso nature of administrative (formal) and adaptive (informal) dynamics in organizations (cf. Smith \& Graetz, 2006). Consistent with Nag et al. (2007), Complexity Leadership Theory recognizes the fundamental tensions in bureaucratic organizations between the desire for structure (administrative) and the need for creative chaos (adaptive) - a notion they refer to as "managed chaos." CLT incorporates the notion of "managed chaos" into leadership research by offering a theory grounded in complexity science - a science based in concepts of tension, chaos, and change. In this way, CLT helps address a key challenge for modern day organizational leaders: the need to "loosen up the organization-stimulating innovation, creativity and responsiveness and learn[ing] to manage continuous adaptation to change-without losing strategic focus or spinning out of control" (Dess \& Picken, 2000, p. 19).

CLT is in line with a genre of leadership approaches which Hunt \& Dodge (2000) call the relational perspective, "at the forefront of emerging leadership thrusts" (p. 445). This perspective includes a focus on networks, lateral, representative and distributive approaches, collectivities, and systems. Like Hunt \& Dodge (2000), we believe there are several reasons why, despite its obvious importance, such a perspective has been overlooked in leadership research.

First, consideration of informal, emergent and adaptive leadership processes convey a lack of "control" that is uncomfortable to us in our desire for predictability and order. It is like Cohen, March, \& Olsen's (1972) shifting soccer field where the rules and the actions are constantly changing. However, in complex systems-such as social systems-the soccer field is no longer even recognizable as such after a while. While we can choose to ignore these realities in our theories and investigation, we cannot wish them away. Therefore, we believe we need to begin exploring these complex issues in earnest, and we offer complexity leadership as a framework for studying and influencing interactive, interdependent, continuously morphing organizational conditions (cf. Rindova \& Kotha, 2001). 
Second, such an approach challenges us in terms of research methods. CLT is a contextual theory of leadership and requires different methods (Osborn et al., 2002). Such research is not suitable to the "quick and easy" questionnaire approach to which we have become accustomed in leadership research (Hunt \& Dodge, 2000). This does not mean, however, that it cannot be tested; only that it may be more difficult. This difficulty, however, "does not justify quick, one-shot studies that fail to recognize important developments in the field" (Hunt \& Dodge, 2000, p. 454). Instead, it requires leadership researchers to explore methodologies that allow us to gather rich, dynamic, contextual and longitudinal data that focus on processes (mechanisms) rather than static, de-contextualized variables. Such methods include qualitative approaches (Plowman et al., 2007; Plowman et al., 2007), simulation and modeling, case studies (e.g., Hunt \& Ropo, 1998), etc.

Third, CLT offers outcomes that have not been studied in leadership previously: emergence and adaptability. Leadership research has primarily emerged out of psychology and social psychology, and therefore has focused heavily on individual traits and personality and small group contexts. In so doing, we have missed out on understanding how groups of interactive, interdependent agents can generate adaptive changes that appear as if spontaneously generated (the null perspective). By offering a meso model focusing on emergence and adaptability in organizational (bureaucratic) contexts, CLT helps in bridging the gap between the OB focus on "people without organizations" and the OT focus on "organizations without people" (Osborn et al., 2002, p. 799).

The CLT framework was developed specifically with the intent to offer a more comprehensive and applicable theory of leadership (cf. Snowden \& Boone, 2007). Therefore we hope its strong practical implications are clear from both the model and the examples we included in this paper. At this point, the practical implications are more "high level," but as we embark on empirical investigation of the elements and facets of CLT we expect to be able to provide more detailed recommendations for how complexity leadership processes work in organizations. Some key practical implications at this stage of development can be summarized as follows: Leaders (individuals throughout the system) in bureaucratic organizational forms need to understand the entangled nature of adaptive and administrative processes and manage this entanglement. Administrative leaders need to design systems and structures that allow the adaptive function (adaptive leadership and complexity mechanisms) to operate effectively. Enabling leaders can help generate the adaptive function by operating in the interface between administrative and adaptive, fostering enabling conditions (e.g., "enabling rules") to promote adaptive dynamics and helping incorporate adaptive outcomes back into the formal administrative systems. Adaptive leaders can influence adaptive dynamics by being adept at "reading" complexity dynamics (e.g., complexity mechanisms) and injecting information into the dynamic in ways that help produce more effective emergent outcomes. All leaders need to understand that leadership is contextual and learn to interact effectively with the dynamic and complex contexts in which they operate.

In conclusion, Complexity Leadership Theory is a meso model perspective that taps informal (CAS) leadership behaviors within the context of larger (bureaucratic) structures. In bureaucratic organizations, these behaviors are often suppressed or ignored (e.g., "Taylor's (1926) famous testimony,"), yet they can be invaluable to an organization seeking to enhance innovation, adaptability, or learning. CLT seeks to integrate these dynamics seamlessly into the hierarchy of a bureaucratic organization, to explain how informal (adaptive) dynamics function, and to describe how these valuable adaptive functions can be fostered within an organization.

\section{References}

Aldrich, 1979 H. E. Aldrich, Organizations and environment, Prentice-Hall, Englewood Cliffs, NJ (1979).

Anderson, 1999 P. Anderson, Complexity theory and organization science, Organization Science 10 (3) (1999), pp. $216-232$.

Arthur, 1989 W. B. Arthur, The economy and complexity. In: D. L. Stein, Editor, Lectures in the sciences of complexity Vol. 1, Addison-Wesley, Redwood City, CA (1989), pp. 713-740.

Baer and Oldham, 2006 M. Baer and G. Oldham, The curvilinear relation between experienced creative time pressure and creativity: Moderating effects of openness to experience and support for creativity, Journal of Applied Psychology 91 (4) (2006), pp. 963-970.

Baker and Gollub, 1990 G. L. Baker and J. P. Gollub, Chaotic dynamics: An introduction, Cambridge University Press, Cambridge (1990).

Barnard, 1938 C. I. Barnard, The functions of the executive, Harvard University Press, Cambridge, MA (1938).

Bluedorn and Jaussi, in press Bluedorn, A. C., \& Jaussi, K. S. (2008). Leaders, followers, and time. The Leadership Quarterly, 19(6), 654-668.

Boal and Schlultz, 2007 K. Boal and P. Schlultz, Storytelling, time, and evolution: The role of strategic leadership in complex adaptive systems, The Leadership Quarterly 18 (4) (2007), pp. 411-428.

Brafman and Beckstrom, 2006 O. Brafman and R. A. Beckstrom, The starfish and the spider: The unstoppable power of leaderless organizations, Penguin Group, New York (2006).

Brown and Gioia, 2002 M. E. Brown and D. A. Gioia, Making things click: Distributive leadership in an online division of an offline organization, The Leadership Quarterly (2002), pp. 397-419.

Bryman, 1996 A. Bryman, Leadership in organizations. In: S. R. Clegg, C. Hardy and W. Nord, Editors, Handbook of Organization Studies, Sage Publications, London (1996), pp. 276-292.

Buckley, 1967 W. Buckley, Sociology and modern systems theory, Prentice-Hall, Inc., Englewood Cliffs, N. J. (1967).

Carley and Hill, $2001>$ K. Carley and V. Hill, Structural change and learning within organizations. In: A. Lomi and E. R. Larsen, Editors, Dynamics of organizational societies, AAAI/MIT Press, Cambridge, MA (2001), pp. 63-92.

Carley and Lee, $1998 \rightarrow$ K. Carley and J. S. Lee, Dynamic organizations: Organizational adaptation in a changing environment, Advances in Strategic Management: A Research Annual 15 (1998), pp. 269-297.

Carley and Svoboda, 1996 K. Carley and D. M. Svoboda, Modeling organizational adaptation as a simulated annealing process, Sociological Methods and Research 25 (1) (1996), pp. 138-168.

Chang and Harrington, 2007 M. H. Chang and J. E. Harrington, Innovators, imitators, and the evolving architecture of problem-solving networks, Organization Science 18 (4) (2007), pp. 648-666.

Chiles et al., 2004 T. Chiles, A. Meyer and T. Hench, Organizational emergence: The origin and transformation of Branson, Missouri's musical the- 
aters, Organization Science 15 (5) (2004), pp. 499-519.

Cilliers, 1998 P. Cilliers, Complexity and postmodernism: Understanding complex systems, Routledge, London (1998).

Clark, $1985>$ P. Clark, A review of the theories of time and structure for organizational sociology, Research in the sociology of organizations 4 (1985), pp. $35-80$.

Cohen et al., 1972 M. D. Cohen, J. G. March and J. P. Olsen, A garbage can model of organizational choice, Administrative Science Quarterly 17 (1972), pp. 1-25.

Conger and Kanungo, 1998 J. A. Conger and R. Kanungo, Charismatic leadership in organizations, Sage, Thousand Oaks (1998).

Cringley, 2002 Cringley, R. X. (Writer) (2002). Triumph of the Nerds: Ambrose Video (ASIN B00006FXQO).

Crozier, 1964 M. Crozier, The bureaucratic phenomenon, University of Chicago Press, Chicago, IL (1964).

Cusumano, 2001 M. Cusumano, Focusing creativity: Microsoft's “Synch and Stabilize" approach to software product development. In: I. Nonaka and T. Nishiguchi, Editors, Knowledge emergence: Social, technical, and evolutionary dimensions of knowledge creation, Oxford University Press, Oxford (2001), pp. 111-123.

Dansereau et al., 1984 F. Dansereau, J. Alutto and F. Yammarino, Theory testing in organizational behavior: The variant approach, Prentice-Hall, Englewood Cliffs, NJ (1984).

Dansereau et al., 1999 F. Dansereau, F. J. Yammarino and J. Kohles, Multiple levels of analysis from a longitudinal perspective: Some implications for theory-building, Academy of Management Review 24 (2) (1999), pp. 346-357.

Davis and Marquis, 2005 G. F. Davis and C. Marquis, Prospects for organization theory in the early twenty-first century: Institutional fields and mechanisms, Organization Science 16 (4) (2005), pp. 332-343.

Day, 1994 D. Day, Raising radicals: Different processes for championing innovative corporate ventures, Organization Science 5 (2) (1994), pp. 148-172.

Dess and Picken, $2000 \rightarrow$ G. Dess and J. C. Picken, Changing roles: Leadership in the 21st century, Organizational Dynamics 28 (3) (2000), pp. 18-34.

DiMaggio and Powell, 1983 P. J. DiMaggio and W. W. Powell, The iron cage revisited: Institutional isomorphism and collective rationality in organizational fields, American Sociological Review 48 (1983), pp. 147-160.

Dougherty and Hardy, 1996 D. Dougherty and C. Hardy, Sustained product innovation in large, mature organizations: Overcoming innovation-toorganization problems, Academy of Management Journal 39 (1996), pp. 1120-1153.

Drath et al., in press Drath, W. H., McCauley, C. D., Palus, C. J., Velsor, E. V., O'Connor, P., \& McGuire, J. B. (2008). Direction, alignment, commitment: Toward a more integrative ontology of leadership. The Leadership Quarterly, 19(6), 635-653.

Drazin et al., 1999 R. Drazin, M. A. Glynn and R. K. Kazanjian, Multilevel theorizing about creativity in organizations: A sense-making perspective, Academy of Management Review 24 (2) (1999), pp. 286-307.

Durand and Calori, 2006 R. Durand and R. Calori, Sameness, otherness? Enriching organizational change theories with philosophical considerations on the same and the other, Academy of Management Review 31 (1) (2006), pp. 93-114.

Dutton and Ashford, 1993 J. Dutton and S. Ashford, Selling issues to top management, Academy of Management Review 18 (3) (1993), pp. $397-428$.

Dutton et al., 2001 J. E. Dutton, S. J. Ashford, R. M. O'Neill and K. A. Lawrence, Moves that matter: Issue selling and organizational change, Academy of Management Journal 44 (4) (2001), pp. 716-736.

Elster, 1998 J. Elster, A plea for mechanisms. In: P. Hedström and R. Swedberg, Editors, Social mechanisms, Cambridge University Press, New York (1998), pp. 45-73.

Fairtlough, $2005 \triangleright$ G. Fairtlough, The three ways of getting things done: Hierarchy, heterarchy and responsible autonomy, Triarchy Press, Greenways, UK (2005).

Finkelstein and Hambrick, 1996 S. Finkelstein and D. C. Hambrick, Strategic leadership: Top executives and their effects on organizations, West Publishing Co, St. Paul, MN (1996).

Floyd and Wooldridge, $2000 \rightarrow$ S. W. Floyd and B. Wooldridge, Building strategy from the middle: Reconceptualizing strategy process, Sage, Thousand Oaks, CA (2000).

Goldstein, 2007 J. Goldstein, A new model of emergence and its leadership implications. In: J. Hazy, J. Goldstein and B. Lichtenstein, Editors, Complex systems leadership theory, ISCE Publishing, Mansfield, MA (2007).

Goodwin, 1994 B. Goodwin, How the leopard changed its spots: The evolution of complexity, Charles Scribner's Sons, New York (1994).

Greenwood and Hinings, $1996>$ R. Greenwood and C. R. Hinings, Understanding radical organizational change: Bringing together the old and new institutionalism, Academy of Management Review 21 (4) (1996), pp. 1022-1054.

Gregory, 2006 T. A. Gregory, An evolutionary theory of diversity: The contributions of grounded theory and grounded action to reconceptualizing and reframing diversity as a complex phenomenon, World Futures 62 (2006), pp. 542-550.

Gronn, 2002 P. Gronn, Distributed leadership as a unit of analysis, Leadership Quarterly 13 (2002), pp. 423-451.

Gryskiewicz, 1999 S. S. Gryskiewicz, Positive turbulence: Developing climates for creativity, innovation, and renewal, Jossey-Bass, San Francisco (1999).

Hambrick, 1989 D. C. Hambrick, Guest editor's introduction: Putting top managers back in the strategy picture, Strategic Management Journal 10 (Special Issue) (1989), pp. 5-15.

Hambrick and Mason, 1984 D. C. Hambrick and P. Mason, Upper echelons: The organization as a reflection of its top managers, Academy of Management Review 9 (2) (1984), pp. 193-206.

Hargadon and Bechky, 2006 A. B. Hargadon and B. A. Bechky, When collections of creatives become creative collectives: A field study of problem solving at work, Organization Science 17 (4) (2006), pp. 484-500.

Hargrave and Van de Ven, 2006 T. J. Hargrave and A. H. Van de Ven, A collective action model of institutional innovation, Academy of Management Review 31 (4) (2006), pp. 864-888.

Hazy, 2007 J. Hazy, Computer models of leadership: Foundations for a new discipline or meaningless diversion?, The Leadership Quarterly, 18(4), 391410 (2007).

Hazy, 2008 J. Hazy, Leadership or luck? The system dynamics of Intel's shift to microprocessors in the 1970s and 1980s. In: M. Uhl-Bien and R. Marion, Editors, Complexity leadership, Part 1: Conceptual foundations, Information Age Publishing, Charlotte, NC (2008), pp. 347-378.

Heckscher, 1994 C. Heckscher, Defining the post-bureaucratic type. In: C. Heckscher and A. Donnellon, Editors, The post-bureaucratic organization: New perspectives on organizational change, Sage, Thousand Oaks (1994).

Heckscher and Donnellon, $1994 \rightarrow$ C. Heckscher and A. Donnellon, Defining the post-bureaucratic type. In: C. Heckscher and A. Donnellon, Editors, The post-bureaucratic organization: New perspectives on organizational change, Sage, Thousand Oaks (1994).

Hedström and Swedberg, 1998a $>$ P. Hedström and R. Swedberg, Social mechanisms: An analytical approach to social theory, Cambridge University Press, Cambridge (1998).

Hedström and Swedberg, 1998b $\triangleright$ P. Hedström and R. Swedberg, Social mechanisms: An introductory essay. In: P. Hedström and R. Swedberg, Editors, Social mechanisms: An analytical approach to social theory, Cambridge University Press, Cambridge (1998), pp. 2-31. 
Heifetz and Laurie, $2001>$ R. A. Heifetz and D. L. Laurie, The work of leadership, Harvard Business Review 79 (11) (2001), pp. $131-141$.

Heifetz and Linsky, $2002 \rightarrow$ R. A. Heifetz and M. Linsky, Leadership on the line: Staying alive through the dangers of leading, Harvard University Press, Boston (2002).

Holland, 1995 J. H. Holland, Hidden order, Addison-Wesley Publishing Company, Reading, MA (1995).

Homans, 1950 G. C. Homans, The human group, Harcourt, Brace \& World, New York (1950).

Hosking, 2001 D. M. Hosking, Organizing, leadership, and skillful process. In: K. Grint, Editor, Leadership: Classical, contemporary, and critical approaches, Oxford University Press, New York (2001), pp. 293-318.

Howell and Higgins, 1990 J. M. Howell and C. A. Higgins, Champions of technological innovation, Administrative Science Quarterly 35 (1990), pp. 317-341.

Hunt and Dodge, 2000 J. G. Hunt and G. Dodge, Leadership deja vu all over again, The Leadership Quarterly 11 (2000), pp. $435-458$.

Hunt and Ropo, 1998 J. G. Hunt and A. Ropo, Multi-level leadership: Grounded theory and mainstream theory applied to the case of General Motors. In: F. Dansereau and F. J. Yammarino, Editors, Leadership: The multiple-level approaches, JAI Press, Westport, CT (1998), pp. $289-328$.

Ireland and Hitt, $1999 \rightarrow$ R. D. Ireland and M. A. Hitt, Achieving and maintaining strategic competitiveness in the 21st century: The role of strategic leadership, Academy of Management Executive 13 (1) (1999), pp. 43-57.

Jaques, 1989 E. Jaques, Requisite organization, Cason Hall, Arlington, VA (1989).

Jermier, 1998 J. M. Jermier, Introduction: Critical perspectives on organizational control, Administrative Science Quarterly 43 (2) (1998), pp. $235-256$.

Johannessen and Aasen, 2007 S. Johannessen and T. M. B. Aasen, Exploring innovation processes from a complexity perspective. Part I: Theoretical and methodological approach, International Journal of Learning and Change 2 (4) (2007), pp. 420-433.

Johannessen and Stacey, $2005 \checkmark$ S. Johannessen and R. D. Stacey, Technology as social object: A complex responsive processes perspective. In: R. D. Stacey, Editor, Experiencing emergence in organisations: Local interaction and the emergence of global pattern, Routledge, London, UK (2005).

Katz and Kahn, 1978 D. Katz and R. L. Kahn, The social psychology of organizations (2nd ed.), John Wiley and Sons, Inc, New York (1978).

Kauffman, 1993 S. A. Kauffman, The origins of order, Oxford University Press, New York (1993).

Kauffman, 1995 S. A. Kauffman, At home in the universe: The search for the laws of self-organization and complexity, Oxford University Press, New York (1995).

Klein et al., 1994 K. J. Klein, F. Dansereau and R. J. Hall, Levels issues in theory development, data collection, and analysis, Academy of Management Review 19 (1994), pp. 195-229.

Krackhardt and Kilduff, 2002 D. Krackhardt and M. Kilduff, Structure, culture and Simmelian ties in entrepreneurial firms, Social Networks 24 (3) (2002), pp. 279-290.

Langston, 1986 C. G. Langston, Studying artificial life with cellular automata, Physica 22D (1986), pp. 120-149.

Leung et al., 2008 A. K. Leung, W. W. Maddux, A. D. Galinsky and C. Chiu, Multicultural experiences enhance creativity, American Psychologist 63 (3) (2008), pp. 169-181.

Levy, 1992 S. Levy, Artificial life: The quest for new creation, Random House, New York (1992).

Lewin, 1952 K. Lewin, Group decision and social change. In: G. E. Swanson, T. M. Newcomb and E. L. Hartley, Editors, Readings in social psychology, Holt, New York (1952), pp. 459-473 rev. ed.

Lichtenstein and Plowman, 2009 B. Lichtenstein and D. Plowman, The leadership of Emergence: A complex systems leadership theory of emergence at successive organizational level, The Leadership Quarterly 20 (4) (2009), pp. 617-630 (this issue).

Lichtenstein et al., 2006 B. Lichtenstein, M. Uhl-Bien, R. Marion, A. Seers, D. Orton and C. Schreiber, Leadership in emergent events: Exploring the interactive process of leading in complex situations, Emergence: Complexity and Organization 8 (4) (2006), pp. 2-12.

Lincoln, 1982 J. R. Lincoln, Intra- and inter-organizational networks, Research in Sociology Organization 1 (1982), pp. 1-38.

Lord, $2008 \rightarrow$ R. G. Lord, Beyond transactional and transformational leadership: Can leaders still lead when they don't know what to do?. In: M. UhlBien and R. Marion, Editors, Complexity leadership, Part 1: Conceptual foundations, Information Age Publishing, Charlotte, NC (2008), pp. 155-184.

Marion, 1999 R. Marion, The edge of organization: Chaos and complexity theories of formal social organizations, Sage, Newbury Park, CA (1999).

Marion, 2002 R. Marion, Leadership in education: Organizational theory for the practitioner, Merrill/Prentice-Hall, Upper Saddle River, NJ (2002).

Marion and Uhl-Bien, 2001 R. Marion and M. Uhl-Bien, Leadership in complex organizations, The Leadership Quarterly 12 (2001), pp. 389-418.

Marion and Uhl-Bien, 2003 R. Marion and M. Uhl-Bien, Complexity theory and al-Qaeda: Examining complex leadership, Emergence: A Journal of Complexity Issues in Organizations and Management 5 (2003), pp. 56-78.

Marion and Uhl-Bien, $2007-$ R. Marion and M. Uhl-Bien, Paradigmatic influence and leadership: The perspectives of complexity theory and bureaucracy theory. In: J. K. Hazy, J. Goldstein and B. Lichtenstein, Editors, Complex systems leadership theory, ISCE Publishing, New York, NY (2007), pp. 143-159.

Markham, 2000 S. Markham, Corporate championing and antagonisms forms of political behavior: An R\&D perspective, Organization Science 11 (4) (2000), pp. 429-447.

Mathieu et al., 2001 J. Mathieu, M. Marks and S. Zaccaro, Multiteam systems. In: N. Anderson, D. Ones, H. Sinangil and C. Viswesvarin, Editors, Handbook of industrial, organizational and work psychology, Organizational Psychology Vol. 2, Sage, London (2001), pp. 289-313.

McKelvey, 2003a B. McKelvey, Emergent order in firms: Complexity science vs. The entanglement trap. In: E. Mitleton-Kelly, Editor, Complex systems and evolutionary perspectives on organizations, Elsevier Science, Amsterdam, NL (2003), pp. 99-125.

McKelvey, 2008 B. McKelvey, Emergent strategy via complexity leadership: Using complexity science and adaptive tension to build distributed intelligence. In: M. Uhl-Bien and R. Marion, Editors, Complexity leadership, Part 1: Conceptual foundations, Information Age Publishing, Charlotte, NC (2008), pp. 225-268.

Meyerson and Scully, 1995 D. E. Meyerson and M. A. Scully, Tempered radicalism and the politics of ambivalence and change, Organization Science 6 (5) (1995), pp. 585-600.

Mumford et al., 2008 Mumford, M., Bedell-Avers, K. E., \& Hunter, S. T. (2008). Planning for innovation: A multi-level perspective. In M. D. Mumford, S. T. Hunter \& K. E. Bedell (Eds.), Research in Multi-level Issues (Vol. 7, pp. 107-154). Bingley, UK: Emerald Group Pub Ltd.

Nag et al., $2007-$ R. Nag, K. G. Corley and D. A. Gioia, The intersection of organizational identity, knowledge, and practice: Attempting strategic change via knowledge grafting, Academy of Management Journal 50 (4) (2007), pp. 821-847.

Nemeth and Ormiston, 2007 C. J. Nemeth and M. Ormiston, Creative idea generation: Harmony versus stimulation, European Journal of Social Psychology 37 (2007), pp. 524-535.

Neustadt and May, 1986 R. E. Neustadt and E. R. May, Thinking in time, Free Press, New York (1986).

Nickerson and Zenger, $2002 \rightarrow$ J. A. Nickerson and T. R. Zenger, Being efficiently fickle: A dynamic theory of organizational choice, Organization Science 13 (5) (2002), pp. 547-566.

Nonaka, 1994 I. Nonaka, A dynamic theory of organizational knowledge creation, Organization Science 5 (1) (1994), pp. 14-37. 
O'Mahony and Ferraro, 2007 S. O'Mahony and F. Ferraro, The emergence of governance in an open source community, Academy of Management Journal 50 (5) (2007), pp. 1079-1106.

Osborn and Hunt, $2007 \checkmark$ R. Osborn and J. G. Hunt, Leadership and the choice of order: Complexity and hierarchical perspectives near the edge of chaos, The Leadership Quarterly 18 (2007), pp. 319-340.

Osborn et al., 2002 R. Osborn, J. G. Hunt and L. R. Jauch, Toward a contextual theory of leadership, The Leadership Quarterly 13 (2002), pp. $797-837$.

Pearce and Conger, $2003 \rightarrow$ C. L. Pearce and J. A. Conger, Shared leadership: Reframing the hows and whys of leadership, Sage, Thousand Oaks (2003).

Perrow, $1970 \triangleright$ C. Perrow, Organizational analysis: A sociological view, Wadsworth Publishing Company, Inc, Belmont, CA (1970).

Perrow, 1972 C. Perrow, Complex organizations, Scott Foresman, Glenview, Ill (1972).

Pfeffer, 1982 J. Pfeffer, Organizations and organization theory, Pittman, Boston (1982).

Plowman et al., 2007 D. Plowman, L. T. Baker, T. Beck, M. Kulkarni, S. Solansky and D. Travis, Radical change accidentally: The emergence and amplification of small change, Academy of Management Journal 50 (3) (2007), pp. 515-543.

Plowman and Duchon, 2008 D. Plowman and D. Duchon, Dispelling the myths about leadership: From cybernetics to emergence. In: M. Uhl-Bien and R. Marion, Editors, Complexity leadership, Part 1: Conceptual foundations, Information Age Publishing, Charlotte, NC (2008), pp. 129-154.

Plowman et al., 2007 D. Plowman, S. Solansky, T. Beck, L. Baker, M. Kulkarni and D. Travis, The role of leadership in emergent, self-organization, The Leadership Quarterly 18 (2007), pp. 341-356.

Rindova and Kotha, 2001 V. P. Rindova and S. Kotha, Continuous "morphing": Competing through dynamic capabilities, form, and function, Academy of Management Journal 44 (6) (2001), pp. 1263-1280.

Roethlisberger and Dickson, 1939 F. J. Roethlisberger and W. J. Dickson, Management and the worker, Cambridge, Harvard University Press, MA (1939).

Rost, 1991 J. C. Rost, Leadership for the twenty-first century, Praeger, London (1991).

Schneider, 2002 M. Schneider, A stakeholder model of organizational leadership, Organization Science 13 (2) (2002), pp. 209-220.

Schneider and Somers, 2006 M. Schneider and M. Somers, Organizations as complex adaptive systems: Implications of Complexity Theory for leadership research, The Leadership Quarterly 17 (4) (2006), pp. 351-365.

Schon, 1983 D. Schon, The reflective practitioner, Avebury, Aldershot (1983).

Schreiber and Carley, $2008 \rightarrow$ C. Schreiber and K. Carley, Leading for innovation and adaptability: Toward a dynamic network analytic theory of knowledge era leadership. In: M. Uhl-Bien and R. Marion, Editors, Complexity leadership, Part 1: Conceptual foundations, Information Age Publishing, Charlotte, NC (2008), pp. 291-332.

Scott, 1981 W. R. Scott, Organization: Rational. natural, and open systems, Prentice-Hall, Englewood Cliffs, NJ (1981).

Selznick, 1949 P. Selznick, TVA and the grass roots, University of California Press, Berkeley, CA (1949).

Selznick, 1957 P. Selznick, Leadership in administration, Harper and Row, New York (1957).

Smith and Graetz, 2006 A. Smith and F. Graetz, Complexity theory and organizing form dualities, Management Decision 44 (7) (2006), pp. 851-870.

Snowden, 2008 D. Snowden, Naturalizing sense-making, Keynote Talk, Organization Science Winter Conference, February 7-9, Squaw Valley, CA (2008).

Snowden and Boone, 2007, November D. J. Snowden and M. E. Boone, A leader's framework for decision-making, Harvard Business Review (2007, November), pp. 68-76.

Stacey, 1993 R. D. Stacey, Strategy as order emerging from chaos, Long Range Planning 26 (1) (1993), pp. 10-17.

Stacey, $2001>$ R. D. Stacey, Complex responsive processes in organizations, Learning and knowledge creation, Routledge, London, UK (2001).

Stacey, 2003 R. D. Stacey, Complexity and group processes: A radically social understanding of individuals, Brunner-Routledge, London, UK (2003).

Streatfield, $2001>$ P. J. Streatfield, The paradox of control in organizations, Routledge, London (2001).

Stumpf and Mullen, 1992 S. A. Stumpf and T. P. Mullen, Taking charge: Strategic leadership in the middle game, Prentice-Hall, Englewood Cliffs, NJ (1992).

Surie and Hazy, 2006 G. Surie and J. K. Hazy, Generative leadership: Nurturing innovation in complex systems, Emergence: Complexity and Organization 8 (4) (2006), pp. 13-26.

Sutton, 2002, Nov/Dec $>$ Robert I. Sutton, Why innovation happens when happy people fight, Ivey Business Journal 67 (2) (2002, Nov/Dec), pp. 1-6.

Taylor's famous testimony before the special House committee, 1926 Taylor's famous testimony before the special House committee, Bulletin of the Taylor Society 11 (3-4) (1926), pp. 95-196.

Thomas et al., $2005 \checkmark$ C. Thomas, R. Kaminska-Labbé and B. McKelvey, Managing the MNC and exploitation/exploration dilemma: From static balance to dynamic oscillation. In: G. Szulanski, Y. Doz and J. Porac, Editors, Advances in strategic management: Expanding perspectives on the strategy process Vol. 22, Elsevier, Amsterdam, NL (2005), pp. 213-250.

Thomke and Nimgade, 2007 S. Thomke and A. Nimgade, IDEO product development, Harvard Business School case, Harvard Business School Publishing, Boston (2007) (9-600-143).

Thompson, 1967 J. D. Thompson, Organizations in action, McGraw Hill, New York (1967).

Trist and Bamforth, 1951 E. Trist and K. W. Bamforth, Some social and psychological consequences of the longwall method of coal-getting, Human Relations 4 (1951), pp. 3-38.

Tsoukas and Chia, 2002 H. Tsoukas and R. Chia, On organizational becoming: Rethinking organizational change, Organization Science 13 (5) (2002), pp. 567-582.

Tsoukas and Hatch, 2001 H. Tsoukas and M. J. Hatch, Complex thinking, complex practice. The case for a narrative approach to organizational complexity, Human Relations 54 (8) (2001), pp. 979-1013.

Uhl-Bien et al., 2007 M. Uhl-Bien, R. Marion and B. McKelvey, Complexity leadership theory: Shifting leadership from the industrial age to the knowledge era, The Leadership Quarterly, 18(4), 298-318 (2007).

von Bertalanffy, 1956 L. von Bertalanffy, General systems theory. In: L. v. Bertalanffy and A. Rapoport, Editors, General systems: Yearbook of the society for the advancement of general systems theory Vol. 1, George Braziller Publishers, New York (1956), pp. 1-10.

Weber, 1947 M. Weber, The theory of social and economic organization (A. H. H. T. Parsons, Trans.), Free Press, Glencoe, IL (1947).

Weick, 1979 K. E. Weick, The social psychology of organizing, Addison-Wesley, Reading, MA (1979).

Weick and Roberts, $1993 \rightarrow$ K. E. Weick and K. Roberts, Collective mind in organizations: Heedful interrelating on flight decks, Administrative Science Quarterly 38 (1993), pp. 357-381.

Woodman et al., $1993 \rightarrow$ R. W. Woodman, J. E. Sawyer and R. W. Griffin, Toward a theory of organizational creativity, Academy of Management Review 18 (2) (1993), pp. 293-321.

Yukl, 2005 G. Yukl, Leadership in organizations (6th ed.), Prentice-Hall, Englewood Cliffs, NJ (2005). 